\title{
An Update to Dialysis-Based Drug Release Testing-Data Analysis and Validation Using the Pharma Test Dispersion Releaser
}

\author{
Marc-Phillip Mast ${ }^{1,2}$, Harshvardhan Modh ${ }^{3}$, Julian Knoll ${ }^{2}$ (D), Elena Fecioru ${ }^{4}$ and Matthias G. Wacker ${ }^{3, *(D)}$ \\ 1 Fraunhofer Institute for Translational Medicine and Pharmacology ITMP, Theodor-Stern-Kai 7, \\ 60596 Frankfurt am Main, Germany; mast@em.uni-frankfurt.de \\ 2 Goethe University, Max-von-Laue-Straße 9, 60438 Frankfurt am Main, Germany; J-Knoll@outlook.com \\ 3 Department of Pharmacy, Faculty of Science, National University of Singapore, 4 Science Drive 2, \\ Singapore 117544, Singapore; phahbm@nus.edu.sg \\ 4 Eurofins PHAST Development GmbH \& Co. KG, Byk-Gulden-Straße 2, 78467 Konstanz, Germany; \\ elena.fecioru@phast.com \\ * Correspondence: matthias.g.wacker@nus.edu.sg; Tel.: +65-65161133
}

check for

updates

Citation: Mast, M.-P.; Modh, H.; Knoll, J.; Fecioru, E.; Wacker, M.G. An Update to Dialysis-Based Drug Release Testing-Data Analysis and Validation Using the Pharma Test Dispersion Releaser. Pharmaceutics 2021, 13, 2007. https://doi.org/ 10.3390/pharmaceutics13122007

Academic Editors: Lenuţa Maria Şuta and Claudia Geanina Watz

Received: 10 November 2021 Accepted: 22 November 2021 Published: 25 November 2021

Publisher's Note: MDPI stays neutral with regard to jurisdictional claims in published maps and institutional affiliations.

Copyright: (c) 2021 by the authors. Licensee MDPI, Basel, Switzerland. This article is an open access article distributed under the terms and conditions of the Creative Commons Attribution (CC BY) license (https:/ / creativecommons.org/licenses/by/ $4.0 /)$.

\begin{abstract}
Currently, a wide variety of complex non-oral dosage forms are entering the global healthcare market. Although many assays have been described in recent research, harmonized procedures and standards for testing their in vitro performance remain widely unexplored. Among others, dialysis-based techniques such as the Pharma Test Dispersion Releaser are developed for testing the release of drugs from nanoparticles, liposomes, or extracellular vesicle preparations. Here, we provide advanced strategies and practical advice for the development and validation of dialysis-based techniques, including documentation, analysis, and interpretation of the raw data. For this purpose, key parameters of the release assay, including the hydrodynamics in the device at different stirring rates, the selectivity for particles and molecules, as well as the effect of excipients on drug permeation were investigated. At the highest stirring rate, a more than twofold increase in the membrane permeation rate (from $0.99 \times 10^{-3}$ to $2.17 \times 10^{-3} \mathrm{~cm}^{2} / \mathrm{h}$ ) was observed. Additionally, we designed a novel computer model to identify important quality parameters of the dialysis experiment and to calculate error-corrected release profiles. Two hydrophilic creams of diclofenac, Voltaren ${ }^{\circledR}$ Emulgel, and Olfen ${ }^{\circledR}$ gel, were tested and provide first-hand evidence of the robustness of the assay in the presence of semisolid dosage forms.
\end{abstract}

Keywords: nanomedicine; release testing; dialysis; semisolids; validation; liposomes; semisolids; creams; topical formulations; dissolution; drug release

\section{Introduction}

For the past decades, drug products comprising fine dispersions of particles have gained a significant market share globally [1-3]. Microparticle and nanoparticle drug products are being used by the pharmaceutical industry and changed the requirements in performance testing. Among others, nanomaterial-based formulations are applied in peroral [4,5], parenteral [3], and topical drug delivery [6-8]. Recent examples include delivery systems of proteins or peptides, the Sars-Cov-2 mRNA vaccines, as well as extracellular vesicle (EV) preparations [3]. Additionally, a considerable number of conventional dosage forms such as ointments, creams, or gels challenge the compendial drug release assays. These preparations are tested using the Vertical Diffusion Cell, the Immersion Cell, or the Flow-Through Cell described by the United States Pharmacopeia (USP). All these methods are characterized by the formation of a static layer of the dosage form perfused by a limited amount of release medium. Although some of these methods reflect the physiology of the administration route to a certain extent, the instruments provide the operator with 
very limited control over the release process. This makes it more difficult to apply these compendial release assays in quality control or drug development.

To date, there are several dialysis-based quality control methods established that enable a highly selective separation of fine particles from the release medium [9]. Among others, the Float-A-Lyzer ${ }^{\circledR}$ (Repligen, Waltham, MA, USA) in combination with USP dissolution apparatus I/II, the USP apparatus IV Dialysis Adapter (Sotax AG, Aesch, Switzerland), and the Pharma Test Dispersion Releaser (PTDR) (Pharma Test Apparatebau AG, Hainburg, Germany) have been described. Initially developed by Wacker and Janas at Goethe University [10], the commercial PTDR (Figure 1) is manufactured by Pharma Test Apparatebau AG (Hainburg, Germany). It is used in combination with a USP dissolution apparatus I/II. While the donor compartment is formed by a small cage holding the dialysis membrane (Figure 1), the dissolution vessel represents the acceptor compartment. The donor and acceptor compartments are constantly agitated at a similar rate.

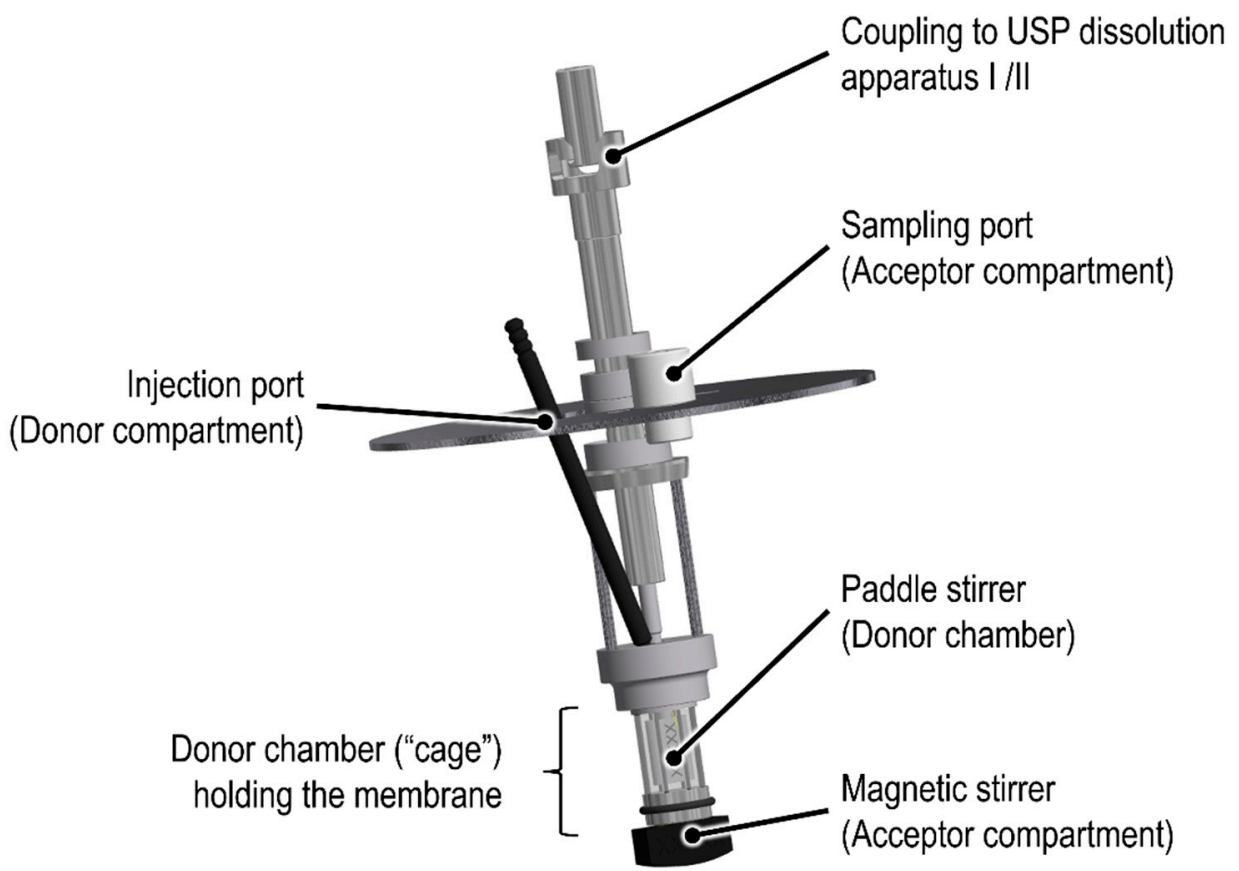

Figure 1. Schematic of the commercial Pharma Test Dispersion Releaser (PTDR).

The instrument was successfully used to investigate the drug release from liposomes [11-13], nanoparticles [5,14,15], microcrystals [16], microspheres [17], and extracellular vesicle (EV) preparations. For many applications, the capability of the assay to predict the in vivo performance was confirmed by correlation of the in vitro and in vivo release rate $[3,5,11,12,14,16,17]$. In the present work, we emphasize differences in the workflow with regards to parameter selection (e.g., stirring rate, membrane material), reference experiments, data evaluation, and data interpretation, when dialysis-based in vitro release tests are developed $[9,18,19]$.

Dialysis involves two kinetic processes with an impact on the release profile, the release kinetics of the drug substance from the carrier (described by the release rate constant $k_{r e l}$ ), and the permeation rate through the dialysis membrane (described by the membrane permeation rate constant $k_{m}$ ). Both processes, together with an illustration of their quantification, are presented in Figure 2. In the following, we lay out a recommended practice and provide an overview of the technical operations that confirm the functionality of the PTDR under various conditions. In addition, we outline reference experiments that minimize the expected analytical errors.

To harmonize the treatment of dialysis-based release data, we used the visual programming language Systems Thinking, Experimental Learning Laboratory with Animation 
(STELLA) to provide a user-friendly interface for the calculation of the membrane permeation rate constant $\left(k_{m}\right)$ and normalization of the release profiles. The dialysis membrane permeation calculator (DIMEC) and the PTDR Release Normalizer ( $\underline{\text { ReNo }}$ ) are available under the Creative Commons License.

Reference experiment
Release experiment

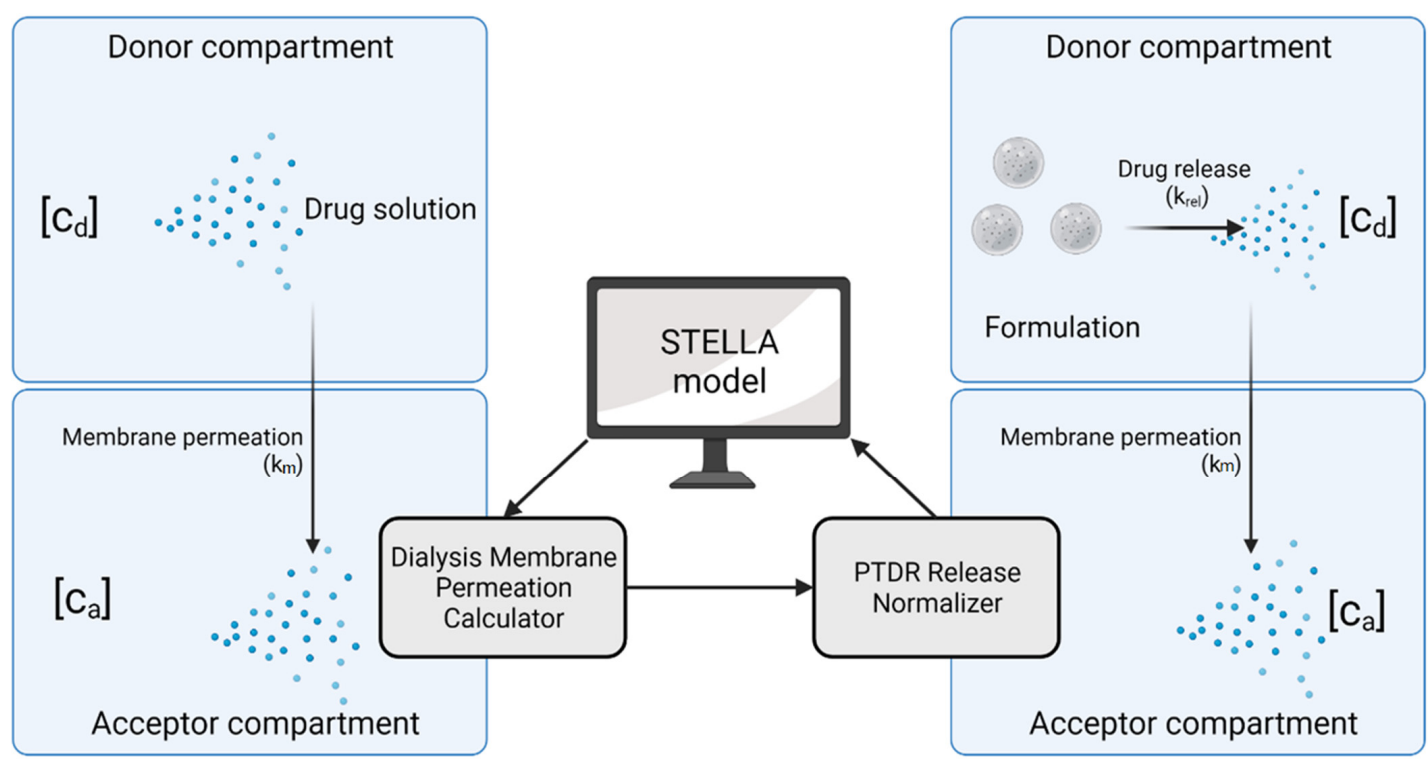

Figure 2. Kinetic processes involved in dialysis. The membrane permeation rate $\left(k_{m}\right)$ is determined in a reference experiment using a drug solution. This membrane permeation rate is later applied in the normalization of the release profile. In this illustration $\left[c_{d}\right]$ represents the drug concentration in the donor compartment and $\left[c_{a}\right]$ the drug concentration in the acceptor compartment. Created with BioRender.com.

\section{Materials and Methods}

\subsection{Chemicals and Materials}

Spectra/Por ${ }^{\circledR} 6$ regenerated cellulose $(\mathrm{RC})$ dialysis membranes with a molecular weight cut-off (MWCO) of $50 \mathrm{kDa}$ and a flat diameter of $28 \mathrm{~mm}$ were purchased from VWR International GmbH (Darmstadt, Germany). A stabilized suspension of reactant-free gold nanoparticles with a diameter of $50 \mathrm{~nm}$ (Sigma-Aldrich Chemie $\mathrm{GmbH}$, Munich, Germany) in $0.1 \mathrm{mM}$ phosphate-buffered saline (PBS) was used for the membrane leakage test. Diclofenac diethylamine (DEA) salt (Cayman Chemical, Ann Arbor, MI, USA) was purchased from Biomol GmbH (Hamburg, Germany) and diclofenac sodium salt was obtained from Sigma-Aldrich Chemie GmbH (Munich, Germany). Olfen ${ }^{\circledR}$ gel (10 mg/g diclofenac sodium, Mepha Pharma AG, Basel, Switzerland), and Voltaren ${ }^{\circledR}$ Emulgel (11.6 mg/g diclofenacDEA, GlaxoSmithKline Consumer Healthcare GmbH \& Co. KG, Munich, Germany) were obtained from a retail pharmacy. Idebenone was purchased from Rxn Chemicals (Hadapsar, India). All the other chemicals were of analytical grade or equivalent and used as received. An Ultra Clear ${ }^{\circledR}$ system (Evoqua water technologies, Günzburg, Germany) was used for water purification in all the experiments.

\subsection{High-Performance Liquid Chromatography}

The diclofenac concentrations were quantified using a Chromaster high-performance liquid chromatography (HPLC) system (VWR Hitachi, Tokyo, Japan). An HPLC pump (5160), a column oven (5310), an autosampler (5260), and a UV-Vis detector (5420) were used. The mobile phase consisted of $62 \%(v / v)$ of acetonitrile and $38 \%(v / v)$ of $0.1 \%(v / v)$ of trifluoroacetic acid in ultrapure water. Separation was carried out in a reversed-phase column (Gemini NX-C18, $5 \mu \mathrm{m}, 250 \times 4.60$ mm, 110 A, Phenomenex Ltd., Aschaffenburg, 
Germany). The flow rate was set to $1 \mathrm{~mL} / \mathrm{min}$ and a temperature of $30^{\circ} \mathrm{C}$ was maintained over the run time of $12 \mathrm{~min}$. The detection wavelength was $276 \mathrm{~nm}$ [20].

The samples containing bovine serum albumin (BSA) were diluted with the sample solvent comprising $62 \%(v / v)$ of acetonitrile and $38 \%(v / v)$ of $0.01 \%(v / v)$ of trifluoroacetic acid in ultrapure water. They were incubated for $30 \mathrm{~min}\left(750 \mathrm{rpm}, 16^{\circ} \mathrm{C}\right)$ using a Thermal Shake lite (VWR International GmbH, Darmstadt, Germany). The reduced amount of acid was used to prevent the degradation of the diclofenac. Next, the precipitated protein was removed by centrifugation $\left(14,000 \times g \mathrm{rpm}, 15 \mathrm{~min}, 16^{\circ} \mathrm{C}\right)$ using a Centrifuge $5430 \times g \mathrm{R}$ with an FA-45-30-11 rotor (Eppendorf AG, Hamburg, Germany). The supernatant was transferred into HPLC vials and a volume of $40 \mu \mathrm{L}$ was injected into the HPLC system. The samples without proteins were diluted similarly and a volume of $40 \mu \mathrm{L}$ was injected without further treatment. The linearity was demonstrated in a concentration range from $0.12-30 \mu \mathrm{g} / \mathrm{mL}$ for both the diclofenac salts. The limit of detection (LOD) and limit of quantitation (LOQ) were determined to be 24 and $80 \mathrm{ng} / \mathrm{mL}$, respectively.

\subsection{Size Exclusion Chromatography}

The BSA was quantified using a Chromaster HPLC system (VWR Hitachi, Tokyo, Japan) equipped with a pump (5160), an autosampler (5260), a column oven (5310), and a UV-Vis detector module (5420). The flow rate was set to $0.9 \mathrm{~mL} / \mathrm{min}$ and a detection wavelength of $280 \mathrm{~nm}$ was used. The column temperature was adjusted to $25^{\circ} \mathrm{C}$. A PBS solution (pH 6.8, $0.25 \%$ sodium azide) was used as the mobile phase. A volume of $50 \mu \mathrm{L}$ was injected into the HPLC system. For this separation, a Yarra SEC-3000 column ( $3 \mu \mathrm{m}$, $300 \times 7.8 \mathrm{~mm}, 200$ A, Phenomenex Ltd., Aschaffenburg, Germany) was used. Linearity was demonstrated in a range from $20-500 \mu \mathrm{g} / \mathrm{mL}$.

\subsection{Drug Solubility}

The solubilities of diclofenac-DEA and diclofenac sodium were determined in different media with a modified shake-flask method. A volume of $4 \mathrm{~mL}$ of each medium was filled into glass vials with an excess of the drug substance. The vials were incubated at $37^{\circ} \mathrm{C}$ (INCU-Line ${ }^{\circledR}$ Standard IL 68 R, VWR International GmbH, Darmstadt, Germany) for $24 \mathrm{~h}$ under constant stirring with a multi-position magnetic stirrer (Cimarec ${ }^{\mathrm{TM}}$ Poly 15, Fisher Scientific $\mathrm{GmbH}$, Schwerte, Germany) at $550 \mathrm{rpm}$. After $24 \mathrm{~h}$, the solid excess was separated with a polytetrafluoroethylene (PTFE) syringe filter ( $13 \mathrm{~mm}$ diameter, $0.45 \mu \mathrm{m}$ pore size, VWR International GmbH, Darmstadt, Germany). The filtrates were diluted and analyzed by HPLC (see Section 2.2). The PTFE filters were saturated with $1 \mathrm{~mL}$ of drug suspension before the samples were collected. These solubility experiments were carried out at $32{ }^{\circ} \mathrm{C}$ and all the experiments were performed in triplicates.

\subsection{Technical Operations}

All the experiments were carried out with a commercial PTDR system (Pharma Test Apparatebau AG, Hainburg, Germany) in a PTWS 120 S dissolution apparatus II (Pharma Test Apparatebau AG, Hainburg, Germany) following the specifications of the USP. A mini-vessel $(250 \mathrm{~mL})$ following the specifications of the Chinese Pharmacopeia [21] was used as the acceptor compartment. The vessels were filled with $120 \mathrm{~mL}$ of filtered and degassed $\left(40^{\circ} \mathrm{C}, 300 \mathrm{mbar}, 30 \mathrm{~min}\right)$ medium. The membrane was pre-treated according to the instructions of the manufacturer, mounted around the donor chamber, and sealed with two O-rings. The volume added to the donor compartment was $3.4 \mathrm{~mL}$, leading to a total volume of $123.4 \mathrm{~mL}$ in the final setup. The sampling volume, time points, temperature, and stirring rates are described in the later sections of this article. The donor chamber featured a surface area of $10.95 \mathrm{~cm}^{2}$. The thickness of the RC membrane was $0.0065 \mathrm{~cm}$.

\subsubsection{Membrane Leakage Test Using Gold Nanoparticles}

The PTDR setup is commonly used for testing the drug release from fine particles or vesicles. The membrane leakage test evaluates the retention of the particle population 
of interest by the membrane. Gold nanoparticles with a diameter of $50 \mathrm{~nm}$ were used as a standard. A volume of $3.4 \mathrm{~mL}$ of the liquid dispersion was injected into the donor chamber which was sealed by an RC membrane (50 kDa). PBS (0.1 mM) was filled into each mini-vessel and samples with a volume of $1 \mathrm{~mL}$ were collected after 1, 2, 4, 8, and $24 \mathrm{~h}$. After $24 \mathrm{~h}$, the RC membrane was punctured with a scalpel blade and, after $30 \mathrm{~min}$, a $1 \mathrm{~mL}$ sample was collected. Additionally, one negative control (a setup without the addition of gold nanoparticles into the donor chamber) and one positive control (a setup with the membrane being punctured at the beginning of the experiment) were tested. The samples were analyzed using a Zetasizer Nano ZS (Malvern Instruments GmbH, Herrenberg, Germany). Additionally, the particle concentration was measured at a wavelength of $535 \mathrm{~nm}$ in a UV-Vis spectrophotometer (U-3000 Spectrophotometer, Hitachi, Tokyo, Japan). The dissolution apparatus operated at $37 \pm 0.5^{\circ} \mathrm{C}$ and $100 \mathrm{rpm}$.

Before quantification by UV-Vis spectroscopy, a wavelength scan was performed in a range from 300-700 $\mathrm{nm}$ at a rate of $300 \mathrm{~nm} / \mathrm{min}$, and linearity was confirmed for the expected concentration range. To use the Zetasizer Nano ZS to determine gold nanoparticles quantitatively, the derived photon count rate was used. For monodispersed nanoparticles smaller than the laser wavelength $(633 \mathrm{~nm})$, the intensity of the scattered light I is proportional to the concentration of the nanoparticles in the sample [22,23]. This mathematical relationship is described by the Rayleigh equation (Equation (1)):

$$
I=I_{0} \cdot \alpha \cdot \frac{m^{2}-1}{m^{2}+2} \cdot d^{6} \cdot c
$$

where $I_{0}$ is the incident light intensity, $\alpha$ is an instrument coefficient, $m$ is the refractive index, $d$ is the particle diameter, and $c$ is the particle concentration. The instrument measures the derived photon count rates, which are a surrogate for the scattered light intensity. It can be used to estimate the particle concentration. The measurements were conducted in triplicate at a fixed position in the center of the cuvette using the parameter summarized in Table 1. Before each measurement, the temperature was equilibrated for $120 \mathrm{~s}$ to $25.0^{\circ} \mathrm{C}$. Linearity was confirmed in the expected range of dilution.

Table 1. Parameters used for the DLS measurement.

\begin{tabular}{ccc}
\hline Parameter & Description & Value \\
\hline Refractive index & Gold nanoparticles & 0.200 \\
Absorbance & Gold nanoparticles & 3.320 \\
Dispersant temperature & Water & $25.0^{\circ} \mathrm{C}$ \\
Refractive index of the dispersant & Water & 1.330 \\
Viscosity of the dispersant & Water & 0.8872 \\
Measurement angle & Backscatter & $173^{\circ}$ \\
Positioning method & Fixed position & 4.65 \\
Repeated measurements & - & 3 \\
\hline
\end{tabular}

These parameters are commonly used by the dynamic light scattering (DLS) system for a concentration-independent calculation of the particle size. However, in the present approach, we used the derived photon count rate to determine particle concentrations. Because of the specifics of these measurements, any reproduction of our findings requires this exact configuration.

\subsubsection{Retention of Macromolecules}

Dialysis membranes are commonly characterized by their MWCO. This parameter describes the molecular size of a marker molecule retained by the membrane over a defined period. For the RC membrane with an $\mathrm{MWCO}$ of $50 \mathrm{kDa}$, at least $90 \%$ of BSA with a molecular weight of $66 \mathrm{kDa}$ is retained over $17 \mathrm{~h}$. Protein retention was therefore used to determine the leakage from the PTDR as well. An amount of $100 \mathrm{mg}$ bovine serum albumin (BSA) in $3.4 \mathrm{~mL}$ PBS 7.4 was injected into the donor chamber. The acceptor 
compartment was filled with $120 \mathrm{~mL}$ PBS 7.4. The dissolution tester was operated at $37^{\circ} \mathrm{C}$ and $50 \mathrm{rpm}$. Samples $(0.2 \mathrm{~mL})$ were collected after 1, 2, 3, 4, 6, 17, 20, and $24 \mathrm{~h}$ followed by replenishing the volume with fresh medium. The albumin was quantified using size exclusion chromatography (SEC, Section 2.3).

Additionally, a real-time permeation profile was recorded under similar conditions. The albumin was quantified using an online dip probe UV-Vis spectroscopic measurement system (TIDAS L 520 UV-NIR, Pharmatest Apparatebau AG, Hainburg, Germany). The absorption was measured in a range from 200-400 nm every $5000 \mathrm{~ms}$ (iteration time) and an average absorption was calculated every $25 \mathrm{~s}$ for $24 \mathrm{~h}$. Reference measurements were conducted, and a linear range was observed ranging from $25-500 \mu \mathrm{g} / \mathrm{mL}$ at $277 \mathrm{~nm}$.

\subsubsection{Hydrodynamics in the Acceptor Compartment}

In the PTDR, the donor and acceptor compartments are stirred at similar rates. The acceptor compartment has a larger volume and efficient mixing is required to accurately detect the release. Therefore, the mixing efficiency in the acceptor compartment was evaluated by adding the dye idebenone to the acceptor compartment and measuring the concentration with the online dip probe UV-Vis spectroscopic measurement system (TIDAS L 520 UV-NIR, Pharmatest Apparatebau AG, Hainburg, Germany). For this experiment, a $2 \%(\mathrm{~m} / \mathrm{v})$ sodium dodecyl sulfate (SDS) solution was used as the medium. A volume of $120 \mathrm{~mL}$ was filled into the acceptor chamber while $3 \mathrm{~mL}$ were added to the donor compartment. The online dip probe was aligned parallel to the center of the donor chamber and the measurement was started as soon as $37 \pm 0.5^{\circ} \mathrm{C}$ was maintained. One measurement was performed every $1000 \mathrm{~ms}$ (iteration time), averaging every $5 \mathrm{~s}$ in one value. A wavelength range of $200-650 \mathrm{~nm}$ was used. The total run time was $15 \mathrm{~min}$. After $30 \mathrm{~s}, 0.6 \mathrm{~mL}$ of a $5 \mathrm{mg} / \mathrm{mL}$ idebenone solution in $2 \%$ sodium dodecyl sulfate was added to the acceptor compartment. The mixing efficiency was evaluated at stirring rates of $0,25,50$, and $100 \mathrm{rpm}$. Linearity for the quantification of idebenone at $283 \mathrm{~nm}$ was demonstrated between $0.9-25 \mu \mathrm{g} / \mathrm{mL}$.

\subsubsection{Drug Permeation Studies at Different Stirring Rates}

In dialysis, drug permeation studies are important reference experiments when testing drug formulations for their release properties. The permeation experiments were carried out with diclofenac sodium in PBS at $37^{\circ} \mathrm{C}$ and stirring rates of $0,25,50$, and $100 \mathrm{rpm}$. The acceptor compartment was filled with $120 \mathrm{~mL}$ of PBS. An amount of $5 \mathrm{mg}$ of the drug dissolved in a volume of $3.4 \mathrm{~mL}$ of PBS was used and injected into the donor compartment. The chamber was sealed by an RC membrane (50 kDa MWCO) and two O-rings. The PTDR was mounted into the USP dissolution apparatus II (Pharma Test Apparatebau AG, Hainburg, Germany). The experiments were conducted at $37 \pm 0.5^{\circ} \mathrm{C}$. Samples $(0.2 \mathrm{~mL})$ were collected after $0.125,0.25,0.5,1,2,3,4,5,6,7$, and $8 \mathrm{~h}$ and the volume was replenished with fresh medium. At the end of each experiment, the samples were collected from the donor compartment to ensure that the equilibrium between the donor and acceptor compartments had been reached. The experiments were repeated with $10 \mathrm{mM}$ phosphate buffer $\mathrm{pH} 7.4$ at $32{ }^{\circ} \mathrm{C}$ and $50 \mathrm{rpm}$ for normalization (see Section 3.3.5).

Later steps involved modeling the drug distribution between the donor and the acceptor compartment. To validate our model, we determined the drug concentration after $0.25,0.5$, and $2 \mathrm{~h}$ at $100 \mathrm{rpm}$. The samples were analyzed as described in Section 2.2.

\subsubsection{Selectivity of the Assay for Specific Size Fractions}

The selectivity of the PTDR setup for different molecular sizes enables the retention of molecules bound to proteins in the donor chamber. In a previous investigation, we highlighted the application of dialysis-based separation to distinguish between drug release and the direct transfer of drug molecules from colloids to proteins [13]. To evaluate the separation on a molecular level, the fraction of diclofenac retained by two different concentrations of BSA was tested. The acceptor compartment was filled with $120 \mathrm{~mL}$ of PBS comprising 1 and $10 \mathrm{~g} / \mathrm{L}$ of BSA, respectively. 
An amount of $5 \mathrm{mg}$ of the drug dissolved in a volume of $3.4 \mathrm{~mL}$ of PBS was injected into the donor compartment. The chamber was sealed by an RC membrane (50 kDa MWCO) and two O-rings. The experiments were conducted at $37 \pm 0.5^{\circ} \mathrm{C}$ and $100 \mathrm{rpm}$. Samples $(0.2 \mathrm{~mL})$ were collected after $0.125,0.25,0.5,1,2,3,4,5,6,7$, and $8 \mathrm{~h}$ and the volume was replenished with fresh medium. The samples were analyzed as described in Section 2.2.

\subsection{Performance Testing}

2.6.1. Evaluation of the Influence of Excipients on the Drug Permeation

Semisolid dosage forms are well known for their interactions with surfaces and membranes. Therefore, we evaluated the PTDR method with regards to potential changes in the detected release due to membrane-excipient interactions. For this purpose, we carried out a release experiment using an emulsion gel, followed by the injection of a drug solution into the acceptor compartment.

An amount of $430 \mathrm{mg}$ of Voltaren ${ }^{\circledR} \mathrm{Gel}$, which corresponds to $5 \mathrm{mg}$ diclofenac-DEA, was weighed into the donor chamber and the release medium was added to a total volume of $3.4 \mathrm{~mL}$. The acceptor compartment was filled with $120 \mathrm{~mL}$ phosphate buffer $\mathrm{pH} 7.4$ as the release medium. An RC membrane (MWCO $50 \mathrm{kDa}$ ) was used and the dissolution apparatus was operated at $32 \pm 0.5^{\circ} \mathrm{C}$ and $50 \mathrm{rpm}$. Samples $(0.2 \mathrm{~mL})$ were collected after $0.25,0.5,1,2,3,4,5,6,7,8$, and $24 \mathrm{~h}$, and the volume was replenished with fresh medium. Afterward, an amount of $5 \mathrm{mg}$ diclofenac-DEA dissolved in $0.5 \mathrm{~mL}$ of release medium was added to the donor chamber, and samples were collected as described above. The samples were analyzed as described in Section 2.2.

\subsubsection{Comparative Release Studies of Two Semisolid Dosage Forms}

Each vessel (acceptor compartment) was filled with a volume of $120 \mathrm{~mL}$ medium of a $40 \mathrm{mM}$ acetate buffer $\mathrm{pH}$ 5.3. Olfen ${ }^{\circledR}$ and Voltaren ${ }^{\circledR}$ gels were weighed accurately into the donor chamber corresponding to $5 \mathrm{mg}$ of diclofenac salt. Release medium was added to prefill the donor chamber to a total volume of $3.4 \mathrm{~mL}$ to avoid diffusion into the donor chamber. The dissolution tester operated at $32 \pm 0.5^{\circ} \mathrm{C}$ and $50 \mathrm{rpm}$. Samples $(0.2 \mathrm{~mL})$ were taken at $0.25,0.5,1,2,3,4,5,6,7,8,24,26,28,32$, and $48 \mathrm{~h}$ and the volume was replenished with fresh medium. The samples were analyzed as described in Section 2.2.

\subsection{Data Analysis and Computer Model}

The evaluation of release data obtained by dialysis experiments often requires a correction of the expected analytical error due to the influences of membrane permeation on the release rate. In the following section, we describe data treatment and evaluation using the four-step model [19]. Two different calculations are made using STELLA. The first calculation identifies the membrane permeation rate constant $\left(k_{m}\right)$ for a given experimental design and drug permeation profile. The operator uses the reference experiment with the dissolved drug substance being added to the donor compartment. A second calculation uses this permeation rate to normalize the release profile. Both STELLA models were published under Creative Commons License.

\subsubsection{Modelling Drug Permeation and Normalization}

To calculate $k_{m}$, the dissolved drug is added to the donor compartment, followed by quantification from the acceptor compartment. The four-step model assumes the diffusion of the drug substance through the membrane to follow Fick's law of diffusion [15]. It depends on the concentration gradient between the donor and the acceptor compartment $(\Delta C)$, the volume of the acceptor compartment $\left(V_{a}\right)$, the thickness of the dialysis membrane $(\delta)$, and the surface area of the dialysis membrane separating both compartments $(A)$.

$$
\frac{d C_{a}}{d t}=\left[\frac{k_{m} \cdot A}{\delta \cdot V_{a}}\right] \times[\Delta C]
$$


For the calculation of the surface area of the dialysis membrane $(A)$, the specifications of the PTDR donor cell (radius $r_{d}$ and height $h_{d}$ of the cage cylinder) can be used (Equation (3)).

$$
A=2 \pi \cdot r_{d} \cdot h_{d}
$$

The thickness of the membrane $(\delta)$ depends on the membrane material and is a common specification reported by the manufacturer. The volume in the acceptor compartment $V_{a}$ depends on the size of the vessel, used for the drug release test. In the present investigation, a $250 \mathrm{~mL}$ mini-vessel configuration following the specifications of the Chinese Pharmacopeia [21] was used, resulting in a total volume of $120 \mathrm{~mL}$ in the acceptor compartment. Furthermore, the evaporation of liquid from the dissolution vessel was taken into consideration. Here, we assumed a linear evaporation process over time and corrected $V_{a}$ for each of the calculated time points. The STELLA model interface uses the initial and the final vessel weight $[\mathrm{g}]$ for this calculation. Hence, an identical initial and final vessel weight leads to uncorrected permeation profiles. During the permeation experiment, the concentration of the drug is quantified from the acceptor compartment $\left(C_{a}\right)$. Together with the drug amount injected into the PTDR $\left(Q_{0}\right)$, the concentration in the donor compartment $\left(C_{d}\right)$ can be calculated:

$$
C_{d}(t)=\frac{\left[Q_{0}-C_{a}(t) \cdot V_{a}(t)\right]}{V_{d}}
$$

Replacing the term $C_{d}(t)$ with Equation (4) in Equation (2) leads to:

$$
\frac{d C_{a}}{d t}=\left[\frac{k_{m} \cdot A}{\delta \cdot V_{a}}\right] \cdot\left[\frac{Q_{0}-C_{a}(t) \cdot V_{a}(t)}{V_{d}}-C_{a}(t)\right]
$$

Equation (5) can then be solved analytically as follows:

$$
C_{a}(t)=\left[\frac{Q_{0}}{V_{a}(t)+V_{d}}\right] \cdot\left\{1-\exp \left[\frac{A \cdot k_{m} \cdot\left(V_{a}(t)+V_{d}\right) \cdot t}{\delta \cdot V_{a}(t) \cdot V_{d}}\right]\right\}
$$

For further calculations, Equation (6) was simplified:

$$
C_{a}(t)=C_{\infty} \cdot\left[1-\exp \left(k_{T} \cdot t\right)\right]
$$

with $C_{\infty}$ being the equilibrium concentration, the equation can now be solved resulting in the newly introduced total diffusion coefficient $k_{T}$ (Equation (8)).

$$
k_{T}=\frac{\ln \left(1-\frac{C_{a}(t)}{C_{\infty}}\right)}{t}=\left[\frac{A \cdot k_{m} \cdot\left(V_{a}(t)+V_{d}\right)}{\delta \cdot V_{a} \cdot V_{d}}\right]
$$

Stella Architect ${ }^{\circledR}$ uses linear extrapolation to create a continuous profile from the data points provided by the operator. The computer model calculates one $k_{T}$ value every $3 \mathrm{~s}$, including measured and extrapolated time points. The values $k_{m}$ and $k_{T}$ remain constant for the same dialysate, and experimental conditions (membrane, stirring rate, temperature, medium) [19]. For each $k_{T}, k_{m}$ can be calculated (Equation (9)) as follows:

$$
k_{m}=\left[\frac{k_{T} \cdot \delta \cdot V_{a} \cdot V_{d}}{A \cdot\left(V_{a}(t)+V_{d}\right)}\right]
$$

However, deviations from the assumed first-order permeation are more likely to occur during the early time points and in the plateau phase. Therefore, an average membrane permeation rate constant was calculated in a permeation range from $15-85 \%$ :

$$
k_{m-\text { Average }}=\frac{1}{n_{15 \%-85 \%}} \cdot \sum_{85 \%}^{15 \%} k_{m}
$$


The second calculation uses the average $k_{m}$ to calculate the concentration profile in the donor chamber. To calculate the concentration in the donor compartment, the slope is continuously calculated from every two data points [19]:

$$
\frac{d C_{a}}{d t} \approx \frac{\Delta C_{a}}{\Delta t}=\left[\frac{k_{m} \cdot A}{\delta \cdot V_{a}}\right] \cdot\left[C_{d}(t)-C_{a}(t)\right]
$$

The concentration in the donor compartment is calculated for the acquired data points [19]:

$$
C_{d}(t)=\left(\frac{\Delta C_{a}}{\Delta d t}\right) \cdot\left[\frac{\delta \cdot V_{a}}{k_{m} \cdot A}\right]+C_{a}(t)
$$

Finally, the total quantity of released drug from the formulation $\left(Q_{r}\right)$ is determined:

$$
Q_{r}(t)=C_{d}(t) \cdot V_{d}+C_{a}(t) \cdot V_{a}
$$

\subsubsection{Validation of Drug Permeation Model}

The membrane permeation rate constant $k_{m}$ is applied to estimate drug concentrations in the donor and the acceptor compartment over time. To validate our in silico model of the dialysis process, we calculated $k_{m}$ for the permeation of diclofenac from the drug permeation profile at three different stirring rates $(25,50$, and $100 \mathrm{rpm})$ and compared the predicted with the observed concentration. The absolute average fold error $(A A F E)$ was calculated using Equation (14) [11,14,24-27] with $n$ time points. Additionally, a comparison between the predicted and the observed drug concentration in the donor compartment was made after $0.25,0.5$, and $2 \mathrm{~h}$ at a stirring rate of $100 \mathrm{rpm}$.

$$
A A F E=10^{\frac{1}{n} \cdot \sum \mid \log \frac{\text { predicted value }}{\text { observed value }}+} \mid
$$

\section{Results and Discussion}

Currently, a rising number of complex non-oral dosage forms enter the global healthcare market. As a consequence, there is a need for novel in vitro methodologies to evaluate their quality and safety. Dialysis-based release assays often require significant expertise. Changes in the membrane quality, as well as the influence of the dialysis rate on the release profile, are the most common challenges reported in recent literature.

However, these "urban legends" often ignore other influences on reproducibility, such as the poor standardization of the instrument and release conditions. The PTDR enables in vitro release testing of liquid and semisolid dispersions in a well-defined setup. After normalization of the release profile using the membrane permeation rate constant $k_{m}$, these release profiles are widely unaffected by the dialysis rate and enable an improved comparison between different formulations and formulation qualities. Our present investigation provides an overview of the technical operations that confirm the functionality of the PTDR and serves as a guide for experimental design, validation, data evaluation, and documentation of dialysis-based release experiments.

\subsection{Solubility of Diclofenac Salts in Different Release Media}

The equilibrium solubility of diclofenac in various media has an impact on permeation and release experiments. When determining the membrane permeation rate constant $k_{m}$, the permeation of a drug solution is measured. Hence, the drug substance must be dissolved completely, and sink conditions must be maintained in the donor chamber as well as in the total volume used for the release assay. Table 2 summarizes the solubilities determined in various release media.

To achieve high aqueous solubility, most of the permeation experiments were carried out in PBS at a pH of 7.4 in the presence or absence of BSA. After the addition of $1 \mathrm{~g} / \mathrm{L}$ of BSA, there was no significant increase in the solubility of diclofenac sodium observed (ANOVA) as compared to PBS alone. This seems unsurprising considering the low BSA 
concentration leading to the complexation of approximately $0.7 \%$ of the drug. Only at the higher BSA concentration, a significant increase was observed (ANOVA, $p<0.05$ ). The release of diclofenac from the two semisolid dosage forms was carried out at lowered temperature $\left(32{ }^{\circ} \mathrm{C}\right)$. Solubilities of diclofenac sodium and diclofenac-DEA in $10 \mathrm{mM}$ phosphate buffer differed significantly (ANOVA, $p<0.05$ ), while the difference in $40 \mathrm{mM}$ acetate buffer was negligible. However, the lowered solubility at acidic $\mathrm{pH}$ made the detection of differences more challenging. In summary, the expected influences of $\mathrm{pH}$, temperature, and salt form on drug solubility were found.

Table 2. Equilibrium solubility after $24 \mathrm{~h}$ of two diclofenac salts in different release media. Experiments were conducted in triplicate $(n=3)$. The values are expressed as mean $\pm \mathrm{SD}$.

\begin{tabular}{ccccc}
\hline Release Medium & pH & Temperature & $\begin{array}{c}\text { Diclclofenac } \\
\text { Sodium Salt } \\
{[\mathbf{m g} / \mathbf{m L}]}\end{array}$ & $\begin{array}{c}\text { Diclofenac-DEA } \\
\text { Salt } \\
{[\mathbf{m g} / \mathbf{m L}]}\end{array}$ \\
\hline PBS & 7.4 & $37.0^{\circ} \mathrm{C}$ & $14.2 \pm 0.3$ & - \\
PBS + 1 g/L BSA & 7.4 & $37.0^{\circ} \mathrm{C}$ & $15.2 \pm 0.3$ & - \\
PBS + 10 g/L BSA & 7.4 & $37.0^{\circ} \mathrm{C}$ & $18.5 \pm 0.2$ & - \\
40 mM Acetate buffer & 5.3 & $32.0^{\circ} \mathrm{C}$ & $0.0314 \pm 0.0008$ & $0.0332 \pm 0.0020$ \\
10 mM Phosphate buffer & 7.4 & $32.0^{\circ} \mathrm{C}$ & $13.5 \pm 0.8$ & $10.2 \pm 0.2$ \\
\hline
\end{tabular}

\subsection{Technical Performance of the PTDR}

Before the release of drug formulations was tested, we carried out a number of technical operations with the PTDR. These included a membrane integrity test, the retention of macromolecules, an evaluation of the hydrodynamics in the acceptor compartment as well as a measurement of the selectivity of the method for the size fraction of interest.

\subsubsection{Membrane Leakage Test Using Gold Nanoparticles}

The membrane integrity test requires a stable particle standard that can be reliably quantified from the acceptor compartment. Serving as an indicator for the particle populations retained by the dialysis membrane, a monodisperse size distribution was one key criterium for the selection. Among other potential standards, gold nanoparticles led to the most reliable outcome. When developing this protocol, a number of commercial nanobeads and polymer nanoparticles were tested (Supplementary Table S1). The limited stability of these preparations was one of the most common weaknesses and included agglomeration or release of the dye.

The gold nanoparticles exhibited a particle diameter of $50 \mathrm{~nm}$, representing a suitable lower size limit for many drug delivery systems. The particles were detected photometrically and by using the derived photon count rate in a DLS setup. The negative control was measured in the absence of gold nanoparticles (Figure 3a), while for the positive control, a small incision in the dialysis membrane allowed the particles to leak into the acceptor chamber (Figure 3e).

For all three vessels (Figure $3 \mathrm{~b}-\mathrm{d}$ ), the absorbance of gold nanoparticles was detected after the incision only ( $24 \mathrm{~h}$ sample). This indicates that there was no leakage from the donor into the acceptor compartment over the whole duration of the experiment. The nanoparticles were successfully retained by the dialysis membrane. This was also confirmed by the mean derived photon count rate, detected by the DLS setup (Figure 3f). For the given particle size and laser wavelength, the derived count rate served as a surrogate parameter for the particle concentration. It was below $1000 \mathrm{kcps}$ for all vessels before the incision and increased to values of more than $2000 \mathrm{kcps}$ after the incision, except for the positive control. This provides strong evidence that particles with a size of $50 \mathrm{~nm}$ are retained by the membrane and do not leak into the acceptor compartment. 


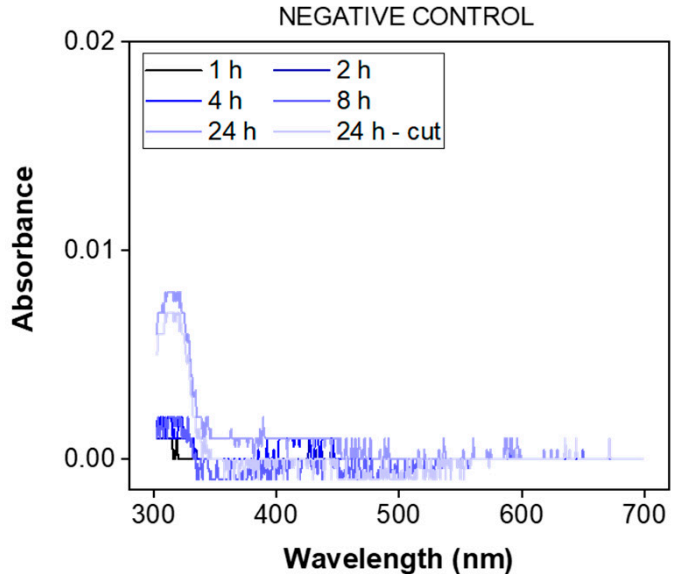

(a)

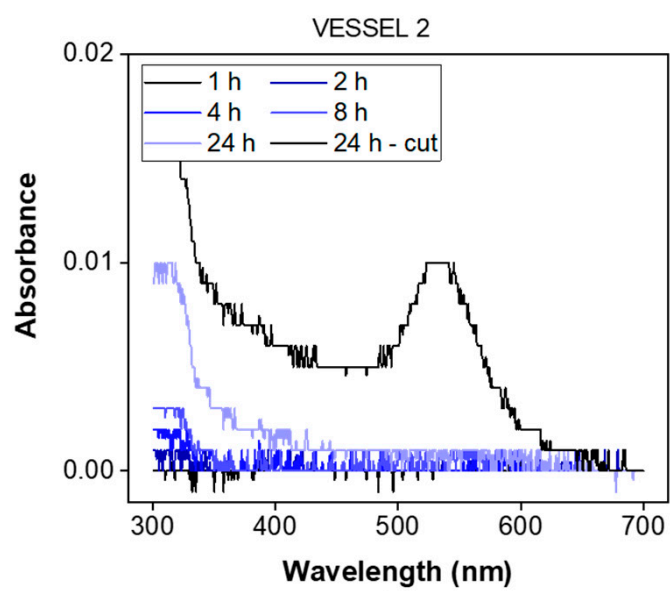

(c)

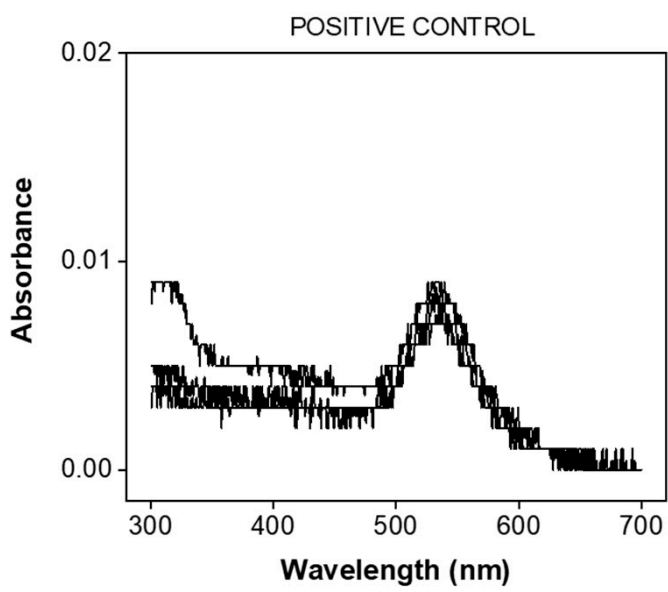

(e)

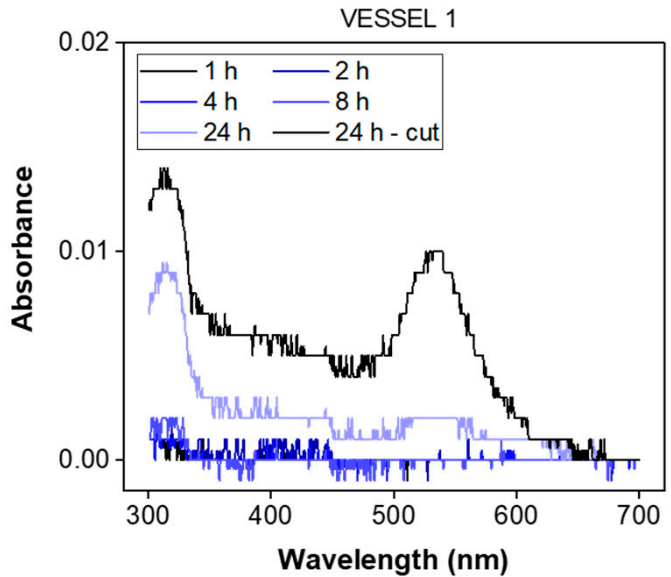

(b)

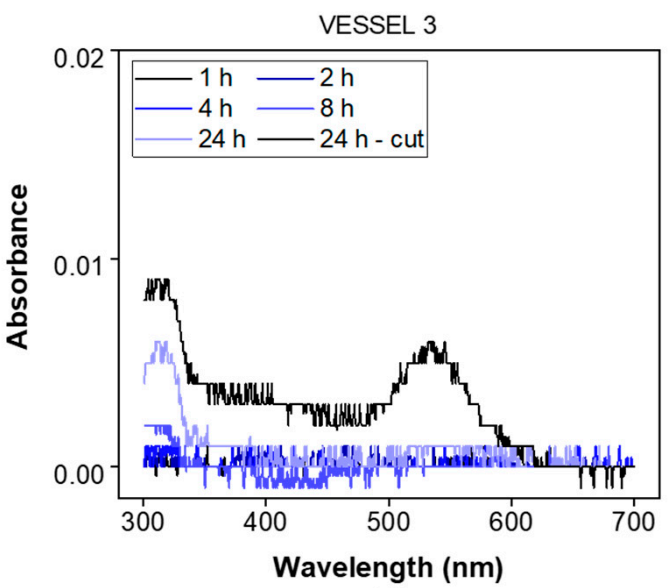

(d)

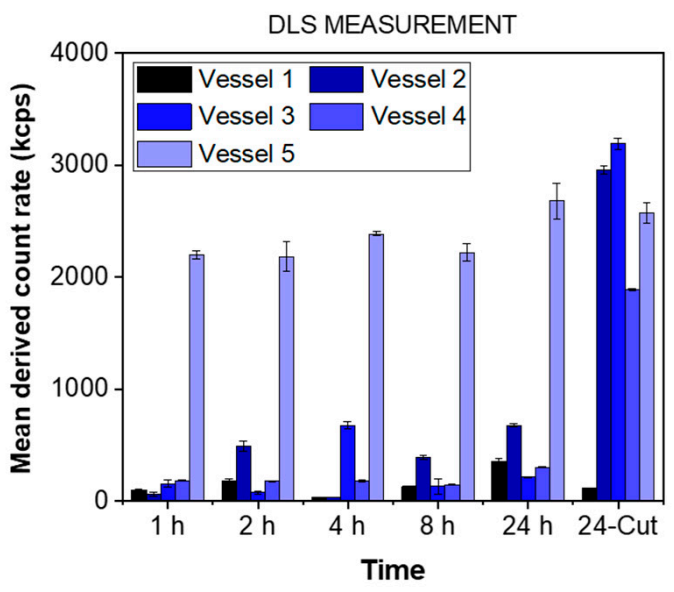

(f)

Figure 3. Membrane integrity test using a dispersion of gold nanoparticles $\left(\lambda_{\max }=535 \mathrm{~nm}\right)$. The samples were analyzed by UV-VIS spectrophotometry at a wavelength of 300-700 nm. The negative control was measured without adding gold nanoparticles (a) while the positive control involved an incision through the membrane before starting the experiment (e). For all other vessels $(\mathbf{b}-\mathbf{d})$, the gold nanoparticles were added to the vessel and the spectrum was recorded at the indicated time points. After $24 \mathrm{~h}$, a small incision through the membrane was performed. The spectra indicating the presence of gold nanoparticles in the acceptor compartment were highlighted in black for all vessels. Additionally, the mean derived count rate in the acceptor compartment was measured indicating the presence of gold nanoparticles in all vessels after the incision but not before this time point, except for the positive control (f). 


\subsubsection{Retention of Macromolecules}

While the pore size reported for syringe filters indicates the average diameter of the filter pores, dialysis membranes are most commonly standardized by their MWCO. This parameter defines a molecular weight where $90 \%$ of a marker molecule was still retained by the membrane after $17 \mathrm{~h}$ [15]. For a $50 \mathrm{kDa}$ dialysis membrane, we used BSA with a molecular weight of $66.5 \mathrm{kDa}$ to measure the retention and quantified the protein by SEC-HPLC (see Section 2.3) and spectrophotometrically using a UV-Vis dip probe (Figure 4).

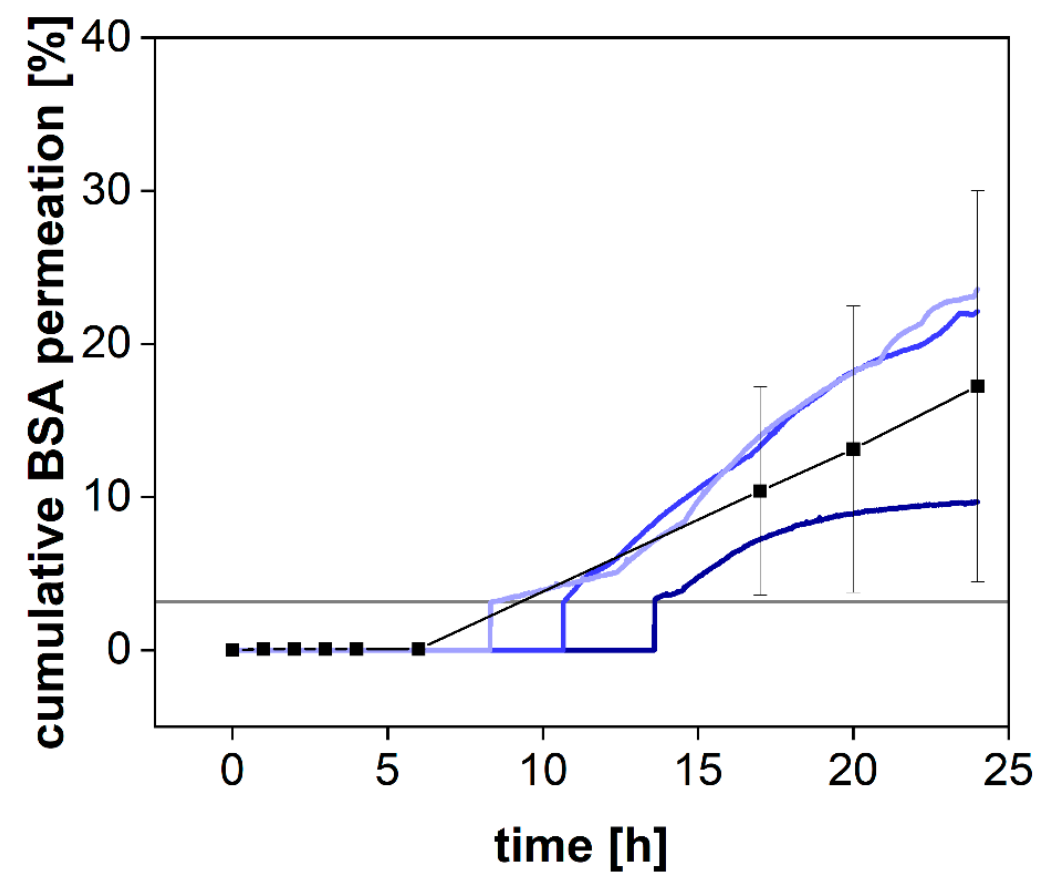

Figure 4. Cumulative permeation of bovine serum albumin (BSA) using SEC-HPLC method (black squares, Mean $\pm \mathrm{SD}, n=3$ ) or an online UV-VIS dip probe (blue colored lines) at $37^{\circ} \mathrm{C}$ and $50 \mathrm{rpm}$ using a $50 \mathrm{kDa}$ RC dialysis membrane. The horizontal grey line denotes the LOQ of the UV-VIS measurement.

BSA was retained by the membrane for the first $8 \mathrm{~h}$ but steadily increased in concentration afterward (Figure 4). Commonly, the MWCO is determined at room temperature under mild agitation of the acceptor compartment only. Consequently, the stirring in the donor compartment, as well as the elevated temperature $\left(37^{\circ} \mathrm{C}\right)$, potentially accelerated the dialysis process. Our findings indicate that leakage from the donor compartment must be considered for the separation of molecules with a molecular volume close to the MWCO of the membrane. In a previous investigation, we reported the quantification of the drug-protein transfer as one potential application of the PTDR [13]. Importantly, these measurements can still be performed. Depending on the ratio between albumin and drug molecules, even a considerable leakage of BSA from the donor chamber does not lead to a corresponding error in the release profile. However, after $15 \mathrm{~h}$ and using a membrane with an MWCO of $50 \mathrm{kDa}$, the leakage would potentially affect the release. Therefore, such investigations should be carried out over a shorter period or using a smaller MWCO (e.g., $30 \mathrm{kDa})$ [13].

\subsubsection{Hydrodynamics in the Acceptor Compartment}

The hydrodynamics in the acceptor compartment of the PTDR has a strong impact on the variability of the measured drug concentration. The common stirring rates of USP apparatus I/II are ranging from $25-100 \mathrm{rpm}$. To determine the impact of the stirring rate on drug distribution in the acceptor compartment, we utilized a dip probe and measured 
the absorbance of the release medium in a fixed position after the addition of a colored dye to the acceptor compartment. The dip probe enables measurement in real-time. Different stirring rates of $0,25,50$, and $100 \mathrm{rpm}$ were tested (Figure 5). Even at a stirring rate of $25 \mathrm{rpm}$, the absorbance remained constant after $1 \mathrm{~min}$. Small fluctuations were observed during this first minute only. At 50 and $100 \mathrm{rpm}$, no fluctuations were observed. Without agitation, no steady absorbance was measured. After $15 \mathrm{~min}$, the absorbance was close to the plateau observed for the other vessels.

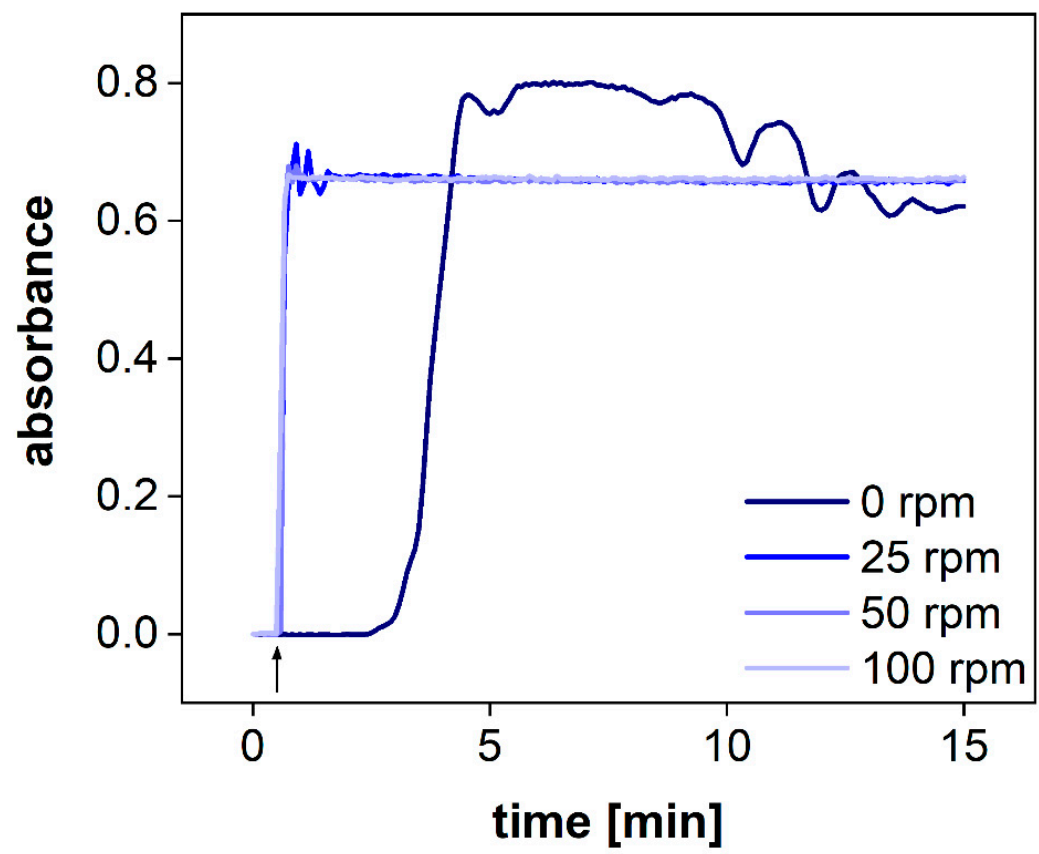

Figure 5. UV-Vis measurements of the acceptor compartment with an online dip probe at $283 \mathrm{~nm}$ at different stirring rates. The arrow denotes that the idebenone solution was spiked into the acceptor compartment.

Consequently, agitation of the acceptor compartment is required for the performance test. However, considering a common sampling time of $2.5-5 \mathrm{~min}$, all stirring rates (25-100 rpm) enable accurate detection of the drug release.

\subsubsection{Permeation Rate at Various Stirring Rates}

The PTDR has the unique feature of accelerating dialysis processes by stirring the acceptor and the donor compartment. Floating, sedimentation, and agglomeration as well as the formation of layer structures in the donor chamber are common challenges of conventional dialysis experiments $[9,16,17]$. Although constant agitation does not always reflect the physiological environment of the administration site, it significantly reduces these effects and leads to improved reproducibility of the measurement $[15,28]$. Furthermore, the stirring accelerates the membrane transport and leads to a higher sensitivity when measuring kinetic processes. In dialysis, a sensitive measurement can only be achieved for dialysis rates exceeding the release rate. To measure this effect for various stirring rates, we dialyzed a solution of diclofenac sodium at 0, 25, 50, $100 \mathrm{rpm}$ (Figure 6). This time-resolved permeation experiment is known as the release response test (RRT) and provides information on the separation time required by this method [29].

Without stirring, diclofenac permeated through the dialysis membrane very slowly and there was a lag time of several minutes before steady-state permeation was reached (Figure 6). Furthermore, the permeated amount was approximately $20 \%$ lower during the release phase and reached a plateau after $6 \mathrm{~h}$. On the contrary, under constant stirring, the plateau was reached after $4 \mathrm{~h}$ only. This separation time represents the time until $100 \%$ of the total dose has been dialyzed. To estimate the sensitivity of the assay, the 
dialyzed fraction per time must be taken into consideration. For all stirring rates, a fraction corresponding to approximately $10 \%$ of the total dose was dialyzed within $7.5 \mathrm{~min}$. The stirring rate of $25 \mathrm{rpm}$ led to a slightly lower permeation rate as compared to $50 \mathrm{rpm}$. This was also reflected by a lowered membrane permeation rate constant. A further increase to $100 \mathrm{rpm}$ did not affect the permeation rate significantly. However, these parameters are strongly affected by other parameters, such as the drug substance, the MWCO, and the membrane material ( $50 \mathrm{kDa}, \mathrm{RC})$. Therefore, general recommendations are difficult to make. The stirring rate must be selected considering the membrane permeation and stability of each formulation and compound. Still, the present investigation indicates that stirring rates of more than $50 \mathrm{rpm}$ may not generally improve the outcome for every membrane type. Furthermore, higher stirring rates are likely to increase the shear stress in the donor chamber and may lead to a change in the release mechanism. Therefore, depending on the sensitivity of the formulation to shear stress, common stirring rates between 25 and $50 \mathrm{rpm}$ are preferred.

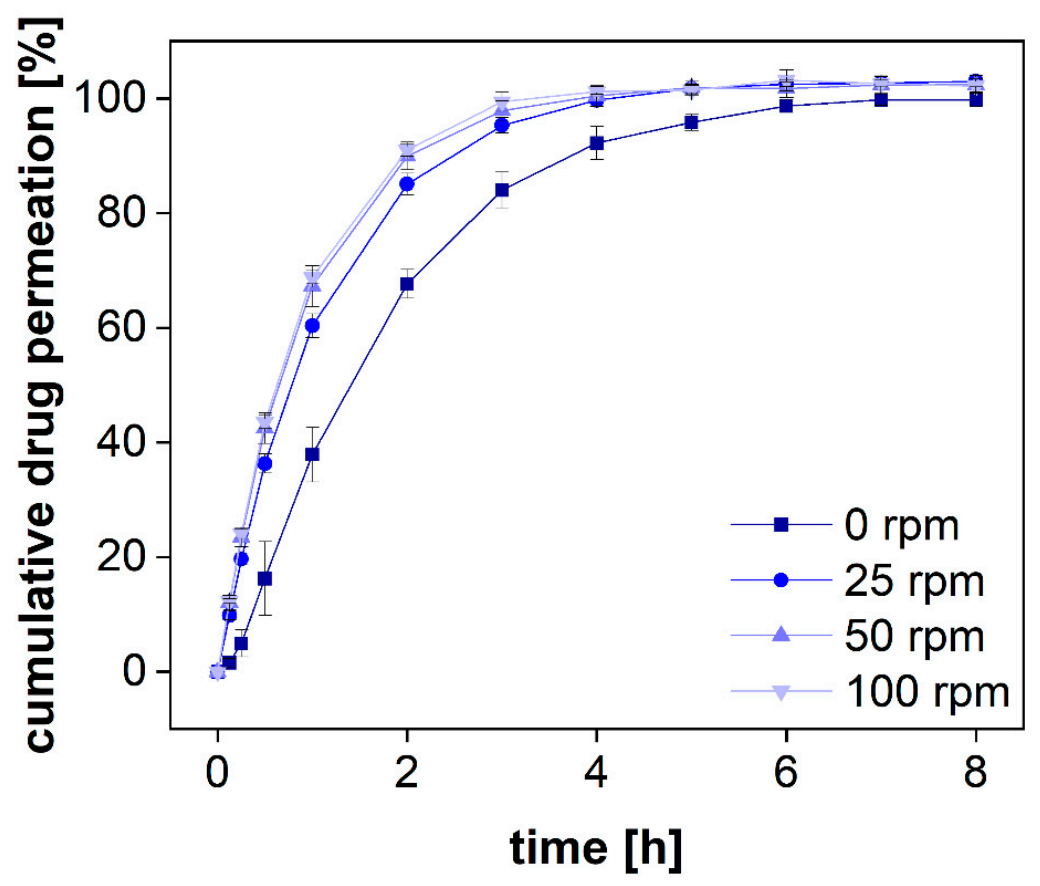

Figure 6. Mean permeation profiles of a diclofenac sodium solution at $37^{\circ} \mathrm{C}$ using an $\mathrm{RC}$ dialysis membrane (MWCO $50 \mathrm{kDa}$ ). Stirring rates were changed accordingly $(n=6)$. Mean $\pm \mathrm{SD}$ is presented.

\subsubsection{Selectivity of the Assay for Specific Size Fractions}

The BSA molecule binds diclofenac with high affinity through ionic and hydrophobic interactions using two unspecific binding sites [30]. A direct comparison between BSA and human serum albumin (HSA) resulted in minor differences between these two proteins, and the plasma protein binding in humans was reported to be 99\% [31]. Therefore, in equilibrium, diclofenac is expected to be bound to proteins at a stoichiometric ratio of 2:1 [30,32]. We used different BSA concentrations to bind a certain fraction of the drug and investigated the specificity of the separation method for this protein-bound fraction. With a molecular weight of $66.5 \mathrm{kDa}, \mathrm{BSA}$ is reliably retained in the donor chamber during the first $8 \mathrm{~h}$ (see Section 3.2.2).

Following the standards of the European Pharmacopeia [33], two compendial buffer systems comprising 1 and $10 \mathrm{~g} / \mathrm{L}$ of BSA were used, respectively. These concentrations are below the physiological albumin concentration of approximately $40 \mathrm{~g} / \mathrm{L}$. Diclofenac sodium was dissolved in PBS 7.4 comprising different amounts of protein. The permeation profiles were measured in the PTDR. The outcome of the investigation is presented in Figure 7 . To quantitatively evaluate the difference in permeation, the area under the curve 
(AUC) was calculated for each permeation profile as well. As expected, at the lower BSA concentration, no significant difference between the profiles of protein-bound and free diclofenac was identified. At a concentration of $1 \mathrm{~g} / \mathrm{L}$, approximately $0.7 \%$ of diclofenac are bound to BSA whereas at a concentration of $10 \mathrm{~g} / \mathrm{L}$ BSA approximately $7 \%$ are in a protein complex. Considering the analytical error indicated by the standard deviation, the difference in the AUCs between both permeation experiments (in the presence and absence of BSA) reflected the theoretical ratio of 0.93 . In the experiment, a ratio of $0.91 \pm 0.02$ was found (Table 3). Hence, the drug was reliably retained by the membrane enabling sensitive detection of the protein-bound and the unbound fraction.

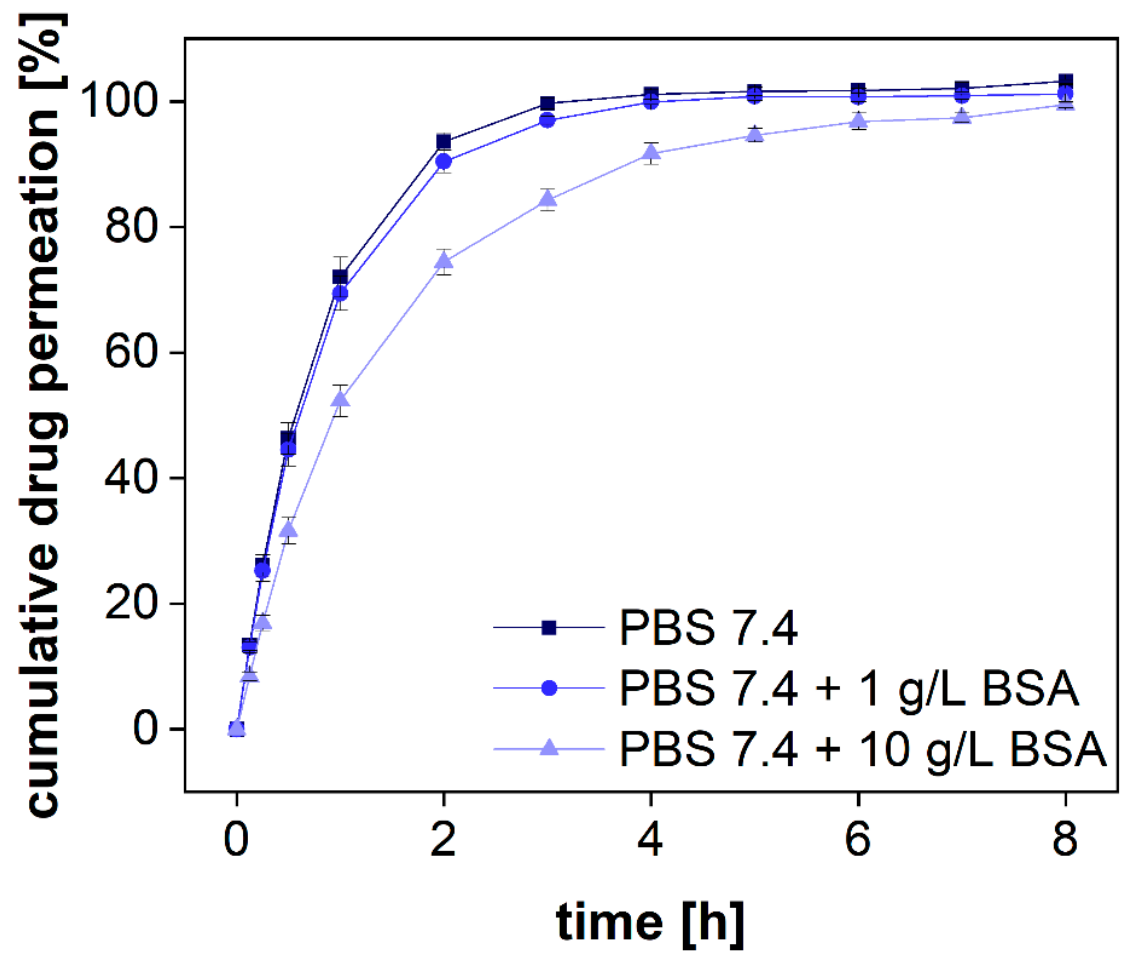

Figure 7. Cumulative permeation of diclofenac sodium with different amounts of BSA in PBS 7.4. A regenerated cellulose membrane (MWCO $50 \mathrm{kDa}$ ) was used to separate the two compartments. The experiment was conducted at $37^{\circ} \mathrm{C}$ at $100 \mathrm{rpm}(n=6)$. Mean values $\pm \mathrm{SD}$ are shown.

Table 3. Calculated AUC of diclofenac sodium permeation in PBS 7.4 with different BSA amounts $(n=6)$.

\begin{tabular}{cccc}
\hline Buffer & $\begin{array}{c}\text { AUC }(\mathbf{0}-\mathbf{8} \mathbf{h}) \\
{[\boldsymbol{\mu g} \times \mathbf{h} / \mathbf{m L}]}\end{array}$ & $\begin{array}{c}\text { SD } \\
{[\boldsymbol{\mu g} \times \mathbf{h} / \mathbf{m L}]}\end{array}$ & Ratio \\
\hline PBS 7.4 & 292 & 2 & - \\
PBS 7.4 + 1 g/L BSA & 292 & 2 & $1.00 \pm 0.01$ \\
PBS 7.4 + 10 g/L BSA & 265 & 4 & $0.91 \pm 0.02$ \\
\hline
\end{tabular}

Considering the increase in BSA permeability over time, the duration of such experiments should not exceed $15 \mathrm{~h}$. Afterward, an increasing analytical error is to be expected. Alternatively, smaller membrane pore sizes should be selected. For small molecules such as diclofenac, an MWCO of 20-30 kDa would still allow efficient separation of the two size fractions and may not be affected by the change in permeability to a similar extent.

\subsection{In Vitro Performance Testing Using the PTDR}

While the first set of experiments (Section 3.2) included procedures to assess the technical performance of the instrument, more studies were conducted to challenge the device 
using a common separation problem. Semisolid dosage forms often contain highly adhesive gelation agents and lipids likely to impact the dialysis process. Therefore, we selected two semisolid drug products, Voltaren ${ }^{\circledR}$ Emulgel and Olfen ${ }^{\circledR}$ gel, for this investigation and studied the influence of the excipients on membrane permeation. The data analysis was carried out using a model-dependent normalization procedure described previously (see Section 2.4) [5,12-15].

\subsubsection{Evaluation of the Influence of Excipients on Drug Permeation}

To study the influence of excipients on drug permeation, the formulation Voltaren ${ }^{\circledR}$ Emulgel was added to the donor chamber of the PTDR and a release experiment was performed (Figure 8a). Of the two semisolid formulations, the emulsion system was more likely to interact with the membrane. After $24 \mathrm{~h}$, a solution of diclofenac was added to the donor chamber and dialyzed under similar conditions (Figure 8a). At neutral $\mathrm{pH}$, the complete dissociation of the weak acid diclofenac increases the aqueous solubility of the drug substance dramatically. Therefore, during the initial $24 \mathrm{~h}$, a rapid dissolution-driven release from the commercial formulation was observed.

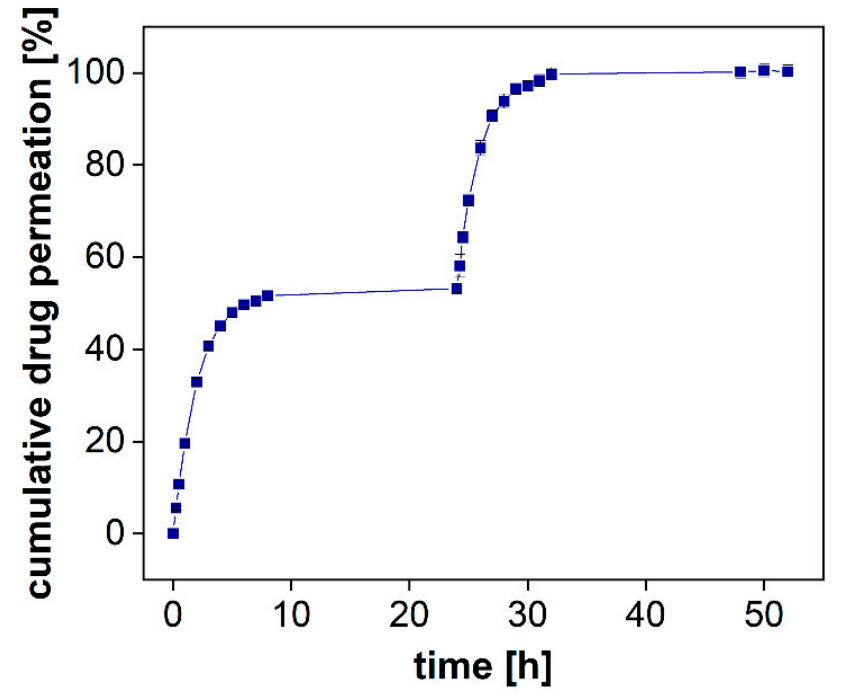

(a)

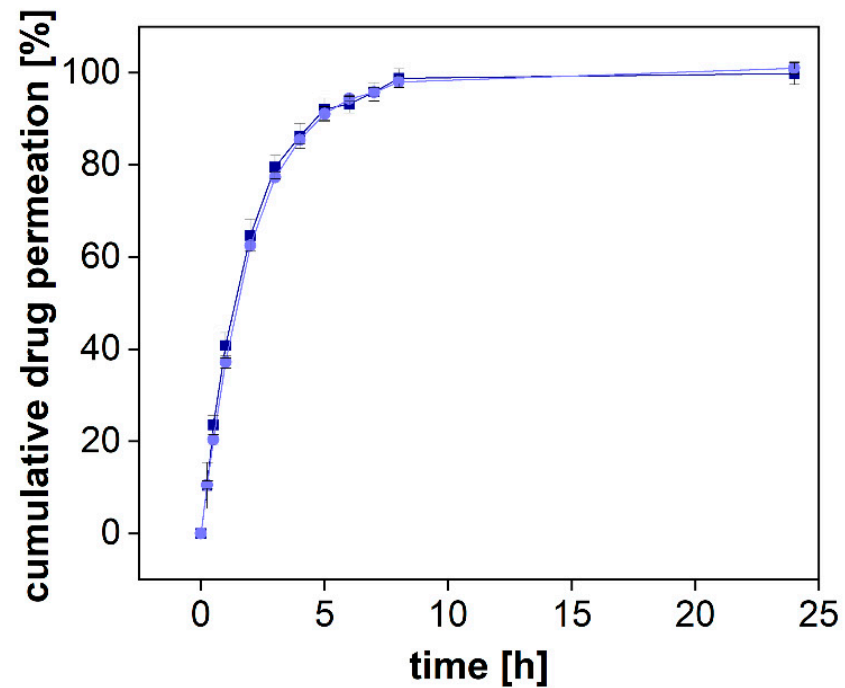

(b)

Figure 8. Cumulative release of diclofenac-DEA from Voltaren Emulgel ${ }^{\circledR}$ with diclofenac-DEA solution spiked into the donor compartment after $24 \mathrm{~h}$. Mean $\pm \mathrm{SD}$ is presented $(n=3)$. On the left, the release profile over $48 \mathrm{~h}$ is presented (a). On the right, the overlay of the initial release and the permeation profile are provided (b).

When adding diclofenac in solution, there was no significant difference between the release and the permeation profiles observed (Figure $8 \mathrm{~b}$ ). This indicates that the formulation had no impact on the dialysis rate. While for most dialysis processes, a strong influence of semisolids on drug separation can be assumed, the PTDR effectively inhibits these membrane interactions and leads to a more reliable release test.

\subsubsection{Documentation of the Experimental Parameters}

Many dialysis experiments reported in the literature do not provide accurate documentation of the exact experimental procedures. In the present investigation, we lay out a recommended methodology. Technical parameters to be reported are summarized in Table 4. They include common information such as the MWCO, or the membrane material, but also an exact description of the donor and the acceptor volume, as well as the preconditioning protocol used for this type of membrane. 
Table 4. Important experimental parameters to be reported.

\begin{tabular}{|c|c|c|}
\hline \multicolumn{2}{|c|}{ Parameter } & Value \\
\hline Membrane characteristics & $\begin{array}{l}\text { Membrane material } \\
\text { MWCO } \\
\text { Membrane thickness } \\
\text { Membrane tube flat width } \\
\text { Storage conditions } \\
\text { Preconditioning protocol of the } \\
\text { manufacturer }\end{array}$ & $\begin{array}{c}\text { Regenerated cellulose } \\
50 \mathrm{kDa} \\
0.0065 \mathrm{~cm} \\
28 \mathrm{~mm} \\
\text { Prewetted in } 0.5 \% \text { sodium azide at } 2-8^{\circ} \mathrm{C} \\
\text { Rinse with water and soak for } 30 \text { min in water } \\
\text { Repligen (USA) }\end{array}$ \\
\hline Dispersion Releaser & $\begin{array}{l}\text { Volume of donor compartment } \\
\text { Volume of acceptor fluid } \\
\text { (Before and after the experiment) } \\
\text { Surface area of the donor cell }\end{array}$ & $\begin{array}{c}3.4 \mathrm{~mL} \\
120 \mathrm{~mL} \text { (mini-vessel configuration) } \\
10.95 \mathrm{~cm}^{2}\end{array}$ \\
\hline Test conditions & $\begin{array}{c}\text { Composition of the release medium } \\
\text { Temperature } \\
\text { Stirring rate } \\
\text { Sampling volume } \\
\text { sampling time points }\end{array}$ & $\begin{array}{c}\text { Various media tested (Materials and Methods) } \\
32{ }^{\circ} \mathrm{C} \text { or } 37^{\circ} \mathrm{C} \text { (Materials and Methods) } \\
0-100 \mathrm{rpm} \text { (Materials and Methods) } \\
200 \mu \mathrm{L} \\
\text { Various (Materials and Methods) }\end{array}$ \\
\hline Sampling injection protocol & Reference experiment & $\begin{array}{c}\text { A volume of } 3.4 \mathrm{~mL} \text { of } \\
\text { an aqueous diclofenac solution } \\
\text { Amount of each semisolid corresponding to } 5 \mathrm{mg} \text { of } \\
\text { diclofenac was weighed into the DR and the donor } \\
\text { chamber was filled with release medium to a total } \\
\text { volume of } 3.4 \mathrm{~mL} \text {. }\end{array}$ \\
\hline
\end{tabular}

\subsubsection{Data Analysis Using Model-Dependent Profile Correction}

The membrane permeation rate constant $\left(k_{m}\right)$ is a performance indicator for the dialysis process and the separation of released drugs from the formulation. It represents an important analytical error and is therefore determined in a permeation experiment (Table 5). The four-step model uses this parameter to normalize the drug release profiles; however, for the application of dialysis-based release experiments in quality control, a specification range for $k_{m}$ would allow the preselection of dialysis membranes to improve reproducibility. Also, normalized release profiles can be directly compared even when measured with membranes from various vendors.

Table 5. Permeation rates calculated for diclofenac sodium at different stirring rates. Each calculation is based on 5 vessels and included 5-6 time points $(n=25$ or $n=30)$.

\begin{tabular}{cccc}
\hline Stirring Rate & $\begin{array}{c}\text { Permeation Rate } \\
\text { Constant }\left[\mathbf{c m}^{2} / \mathbf{h}\right]\end{array}$ & $\begin{array}{c}\text { SD } \\
{\left[\mathbf{c m}^{2} / \mathbf{h}\right]}\end{array}$ & AAFE \\
\hline $0 \mathrm{rpm}$ & $0.99 \times 10^{-3}$ & $0.9 \times 10^{-3}$ & 1.27 \\
$25 \mathrm{rpm}$ & $1.76 \times 10^{-3}$ & $0.10 \times 10^{-3}$ & 1.03 \\
$50 \mathrm{rpm}$ & $2.13 \times 10^{-3}$ & $0.18 \times 10^{-3}$ & 1.03 \\
$100 \mathrm{rpm}$ & $2.17 \times 10^{-3}$ & $0.09 \times 10^{-3}$ & $1.03^{1}$ \\
& & & $1.23^{2}$ \\
\hline
\end{tabular}

${ }^{1}$ Evaluation of the acceptor compartment over the entire permeation profile. ${ }^{2}$ Evaluation of the donor compartment at three time points $(0.25,0.5,2 \mathrm{~h})$.

For the calculation of $k_{m}$, the total permeation rate constant $k_{T}$ is calculated for each time point of the permeation profile. Fluctuations in $k_{T}$ are more likely at the beginning and the end of the permeation experiment due to the initial distribution of the drug as well as the inaccuracies associated with the small concentration differences in the plateau phase. The $k_{T}$ values obtained from the permeation profiles of diclofenac at different stirring rates are presented in Figure 9. For the permeation range from 15 to $85 \%$ of the total dose, there were almost no fluctuations observed. Therefore, we decided to use this range for the 
calculation of $k_{m}$. Evidently, the fluctuations are more pronounced for higher stirring rates, indicating a certain influence of the hydrodynamics on the diffusion rate.

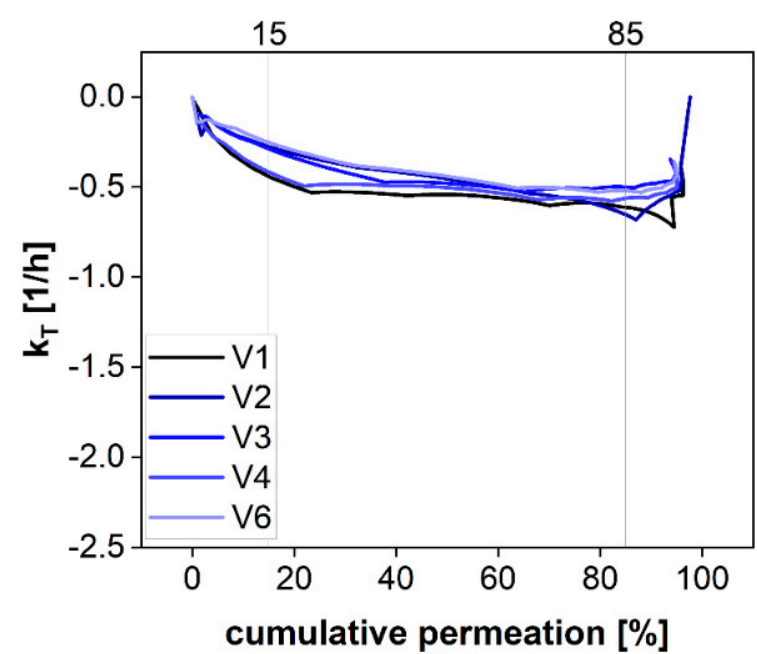

(a)

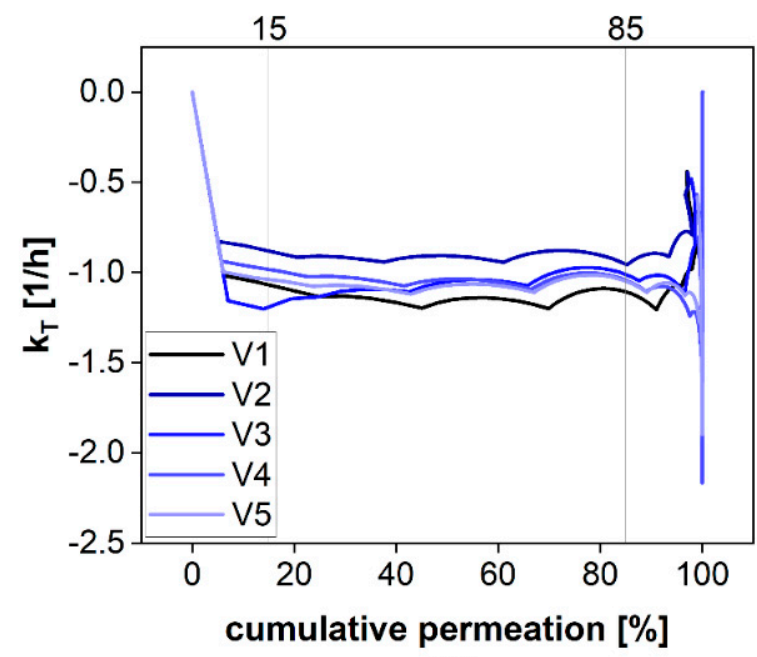

(c)

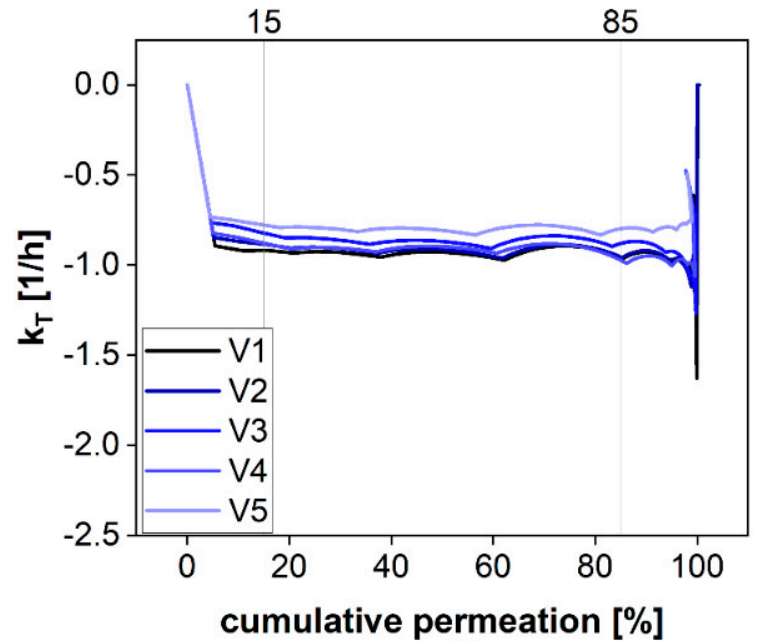

(b)

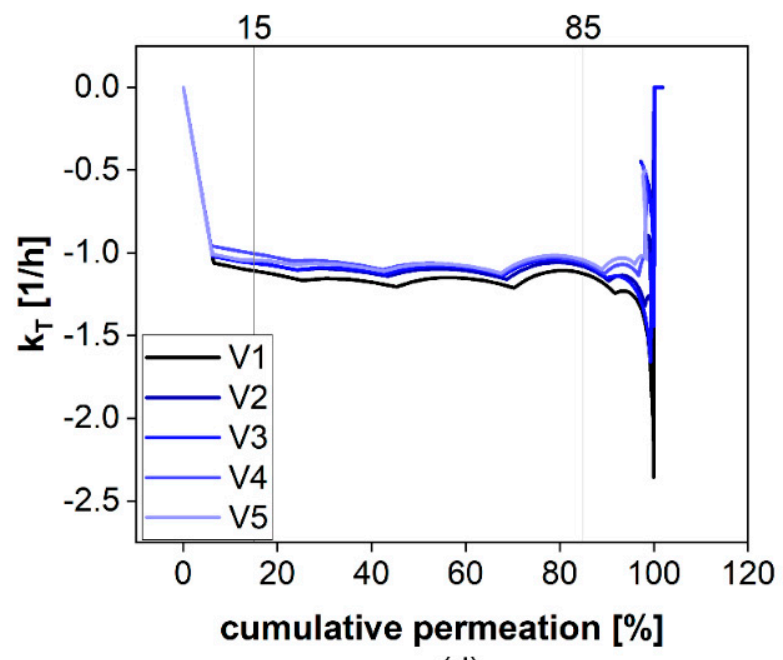

(d)

Figure 9. The calculated $k_{T}$ values at 0 (a), 25 (b), 50 (c), and $100 \mathrm{rpm}(\mathbf{d})$.

To provide a convenient solution, we automated the process of $k_{m}$ calculation and published a user-friendly calculator (DIMEC) under the Creative Commons License. The operator provides the permeation profile, followed by an automated calculation of $k_{m}$. The default settings include the technical parameters of the PTDR, however, other methodologies can be used. The user interface enables the customization of all the input parameters, including the surface area and the volume of the release cell.

\subsubsection{Validation of the Mathematical Model}

To provide evidence for the accuracy of the STELLA model, we compared the permeation profile with the simulated permeation profile represented by the $k_{m}$ value. It indicates the quality of the curve fit. The absolute average fold error (AAFE) is a simple measure of the difference between the simulated and the observed values in a simulation [11,14,24-27]. An AAFE of 1 indicates two identical profiles and values below 2 indicate a successful simulation [26,27]. For the permeation experiments carried out at stirring rates of $25-50 \mathrm{rpm}$, an AAFE of 1.03 was achieved (Table 5). At a stirring rate of $0 \mathrm{rpm}$, the lag time between injection of the solution and the constant drug flux through the membrane led to an increase in the AAFE to 1.27. At the highest stirring rate, the most considerable influence of the 
stirring rate on permeation was as expected. This still resulted in an accurate reflection of the permeation profile with an AAFE of 1.03. To validate our simulation, we collected samples from the donor compartment at the highest stirring rate after $0.25,0.5$, and $2 \mathrm{~h}$ and compared the observed and simulated drug concentrations. This is presented in Figure 10 (d, red line/red triangles). It provides further evidence for the reliability of the mathematical model.

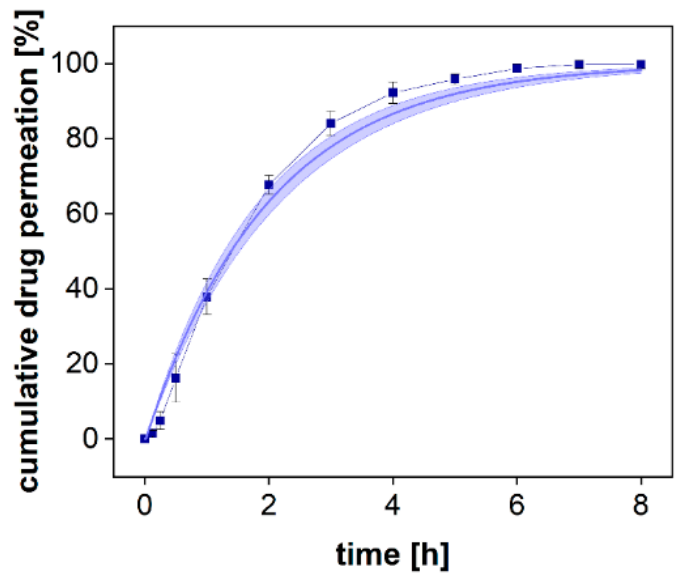

(a)

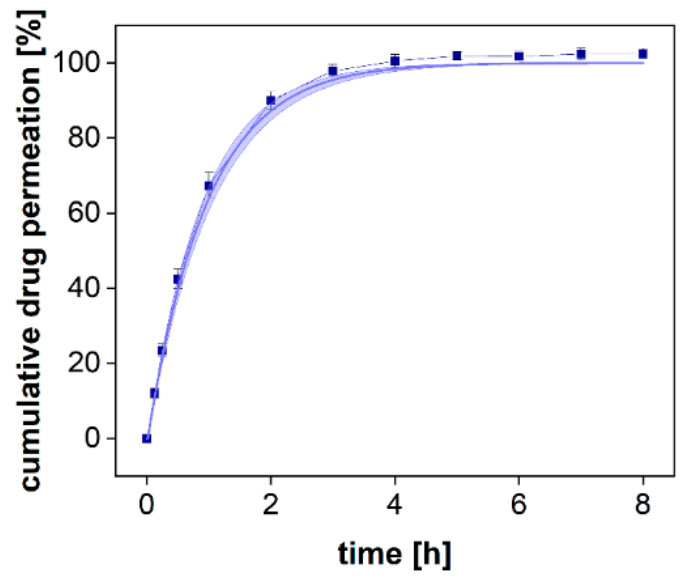

(c)

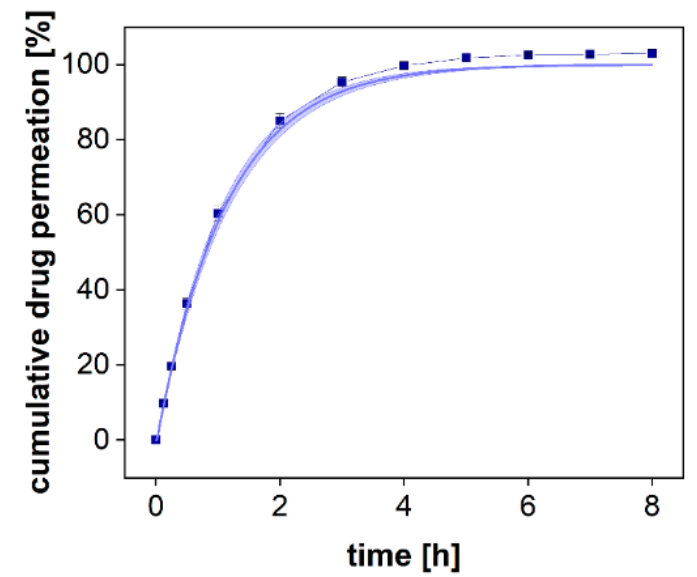

(b)

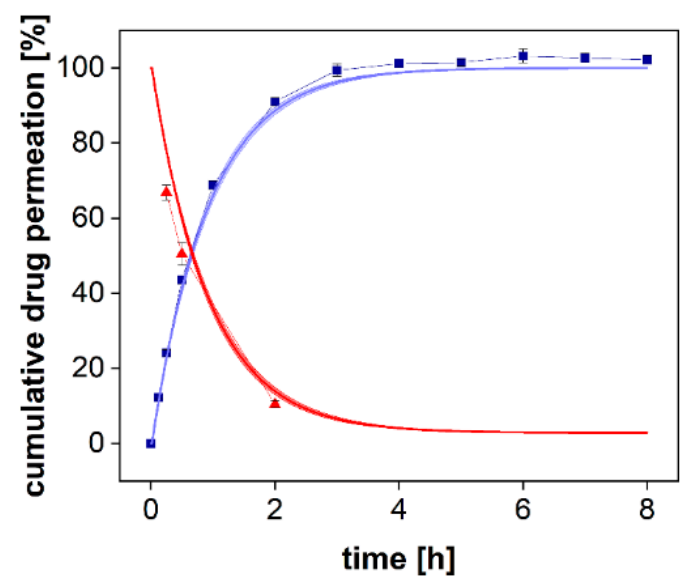

(d)

Figure 10. Comparison of observed and simulated permeation profiles at 0 (a), 25 (b), 50 (c), and $100 \mathrm{rpm}$ (d). The blue squares indicate the mean $\pm \mathrm{SD}(n=6)$ observed cumulative drug permeation and the blue line presents the simulated cumulative drug permeation using the mean $k_{m} \pm \mathrm{SD}$. In (d) the donor compartment was evaluated. The red triangles indicate the observed mean $\pm \operatorname{SD}(n=6)$ with the corresponding simulated relative donor concentration as the red line.

The $k_{m}$ values at 0 and $25 \mathrm{rpm}$ were $0.99 \times 10^{-3} \mathrm{~cm}^{2} / \mathrm{h}$ and $1.76 \times 10^{-3} \mathrm{~cm}^{2} / \mathrm{h}$, respectively (Table 6). At 50 and $100 \mathrm{rpm}$, the permeation rates increased to $2.13 \times 10^{-3}$ $\mathrm{cm}^{2} / \mathrm{h}$ and $2.17 \times 10^{-3} \mathrm{~cm}^{2} / \mathrm{h}$, respectively (Table 5). This confirms the contribution of the stirring rate to membrane transport that is responsible for the higher sensitivity of this release assay. However, at higher stirring rates, the influence was negligible. Therefore, stirring rates of more than $50 \mathrm{rpm}$ should not be selected without confirming the benefit for a specific formulation or membrane pore size.

The average permeation rate constants for each stirring rate (Table 5) were calculated from 5 vessels and included 5-6 measured time points, depending on the number of sampling time points falling into the range of $15-85 \%$ permeation. For the statistical evalua-tion, we considered only time points sustained by quantification and not the extrapolated time points $(>100)$. A significant difference in the membrane permeation rate constant was observed between all $k_{m}$ values except for the difference between 50 and $100 \mathrm{rpm}$ (ANOVA, $p>0.05)$. 
Table 6. List of excipients of Voltaren ${ }^{\circledR}$ Emulgel and Olfen ${ }^{\circledR}$ gel.

\begin{tabular}{ccc}
\hline Excipient & Voltaren $^{\circledR}$ Emulgel & Olfen $^{\circledR}$ Gel \\
\hline Lactic acid & & $\mathrm{X}$ \\
Diisopropyladipate & $\mathrm{X}$ & $\mathrm{X}$ \\
Isopropylalcohol & & $\mathrm{X}$ \\
Sodium metabisulfite & & $\mathrm{X}$ \\
Hydroxyethylcellulose & $\mathrm{X}$ & \\
Hydroxypropylcellulose & $\mathrm{X}$ & \\
Diethylamine & $\mathrm{X}$ & \\
Propylene glycol & $\mathrm{X}$ & \\
Mineral oil & $\mathrm{X}$ & \\
Cocoyl caprylocaprate & $\mathrm{X}$ & \\
Polyoxyl-20-cetostearylether & $\mathrm{X}$ & $\mathrm{X}$ \\
Carbomer & $\mathrm{X}$ & \\
Perfume creme & & \\
Purified water & &
\end{tabular}

\subsubsection{Performance Testing Using Two Semisolid Diclofenac Formulations}

The release of diclofenac is controlled by the aqueous solubility of each salt in the medium. Under sink conditions, there was no significant difference between the two formulations expected. For the performance assay, we selected a slightly acidic $\mathrm{pH}$ value corresponding to the $\mathrm{pH}$ of the human skin (5-6) [34]. Noteworthy, the conditions of the assay, including hydrodynamics, liquid volume, and buffer capacity, do not reflect the topical route of administration. Still, the release profiles provide information on the differences between these two dosage forms and could be used for excipient selection. The composition of the two gels is summarized in Table 6. Olfen ${ }^{\circledR}$ gel comprises a conventional linear colloidal hydrogel structure with a certain amount of isopropyl alcohol embedded into the gel structure, whereas Voltaren Emulgel ${ }^{\circledR}$ is a gelled oil-in-water emulsion. The drug was dissolved in the aqueous phase.

The cumulative drug release from both formulations is presented in Figure 8a. Voltaren ${ }^{\circledR}$ Emulgel released diclofenac more rapidly compared to the Olfen ${ }^{\circledR}$ gel and, within $48 \mathrm{~h}$, reached a plateau at almost $60 \%$, corresponding to the aqueous solubility determined for this release medium at $32{ }^{\circ} \mathrm{C}(0.0314 \pm 0.0008 \mathrm{mg} / \mathrm{mL}$ for diclofenac sodium and $0.0332 \pm 0.0020 \mathrm{mg} / \mathrm{mL}$ for diclofenac-DEA). Olfen ${ }^{\circledR}$ gel released the drug much slower and reached a plateau at approximately $40 \%$. The emulsifying agents present in Voltaren ${ }^{\circledR}$ Emulgel as well as the improved solubility of diclofenac-DEA are the most likely explanation. A delaying effect of the emulsion system on dialysis could not be detected. Furthermore, it is unlikely that, when using the highly soluble salt of diclofenac, the emulsion system had a strong impact on the drug release.

Subsequently, we calculated the $k_{m}$ values using the DIMEC programmed in STELLA [19]. The permeation rate constants of the diclofenac sodium and diclofenac-DEA were 1.54 $\pm 0.12 \times 10^{-3} \mathrm{~cm}^{2} / \mathrm{h}$ and $1.75 \pm 0.19 \times 10^{-3} \mathrm{~cm}^{2} / \mathrm{h}$, respectively. Subsequently, we normalized the release profiles for each formulation using the PTDR ReNo. This calculator is provided under Creative Commons License as well.

After normalization (Figure 11b), a burst release of 16\% from Olfen ${ }^{\circledR}$ gel and $34 \%$ from Voltaren ${ }^{\circledR}$ Emulgel were observed. It is evident that the release behavior of diclofenac from both hydrogels was widely driven by drug solubility and that the emulsion system represents a minor influence on the release. 


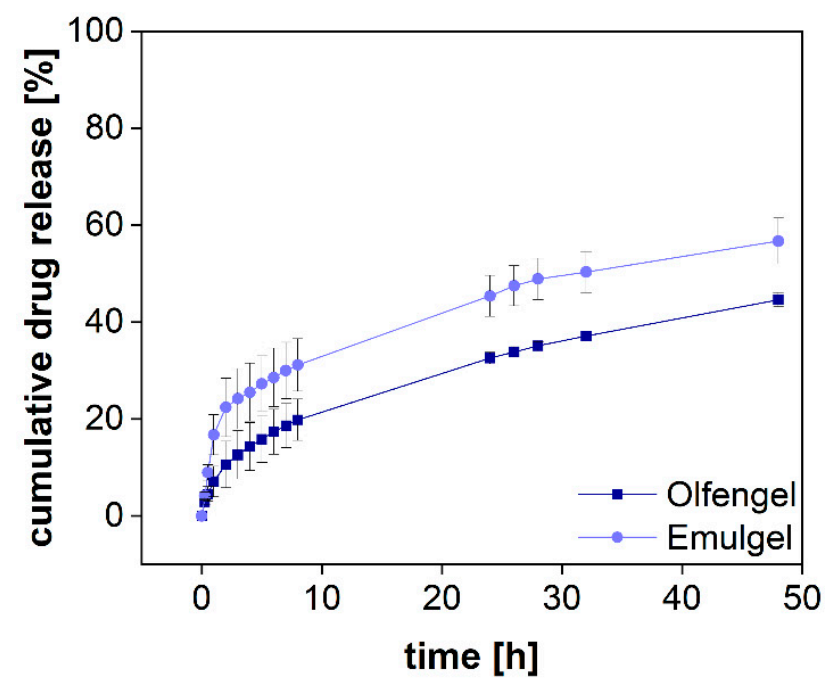

(a)

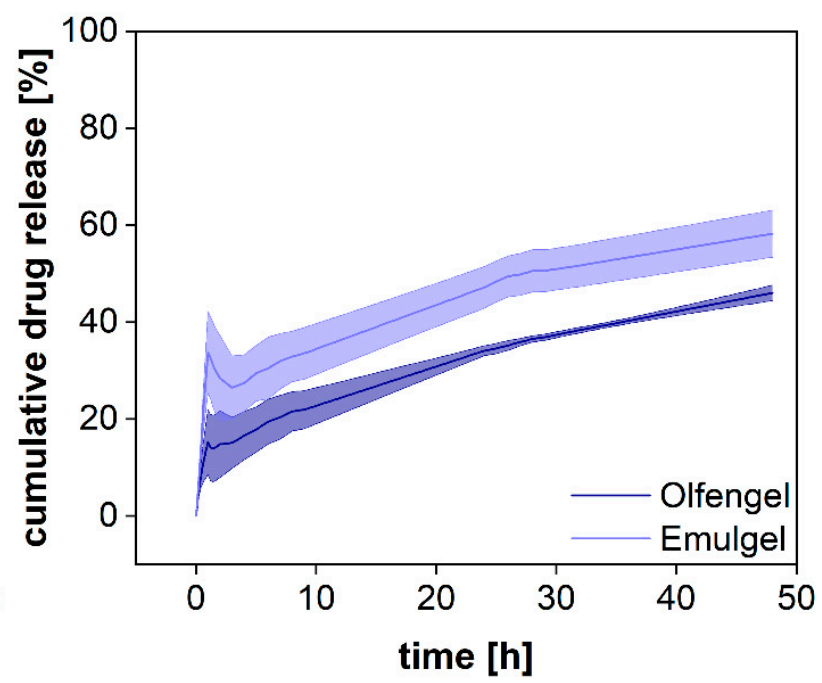

(b)

Figure 11. Cumulative release of two different diclofenac semisolid formulations. Measured diclofenac released into the acceptor compartment $((\mathbf{a}), n=4)$ and normalized release profile $(\mathbf{b})$. Mean $\pm \mathrm{SD}$ is shown.

\section{Conclusions}

Most dialysis-based performance assays demand a higher level of understanding from the operator. However, the requirements do not differ considerably from other dissolution tests. The selectivity of the separation method for the dissolved drug (e.g., by separating molecules with a specific molecular volume) and the separation time commonly have a strong impact on the release profile. Since most dialysis methods reported in previous research do not control hydrodynamics in the donor chamber and other influences, their limited reliability is not surprising. In the present investigation, we provide evidence for the reliability of a well-designed experimental setup, together with a dedicated mathematical methodology and documentation. To make it easier to comply with these high standards, we provide two computer models that can be customized for other dialysis-based release tests as well.

Supplementary Materials: The following are available online at https:/ /www.mdpi.com/article/10 .3390 / pharmaceutics13122007/s1. Table S1: Commercial standards evaluated for testing the leakage of particles from the PTDR.

Author Contributions: Conceptualization, M.-P.M. and M.G.W.; software, M.-P.M., H.M., J.K. and E.F.; investigation, M.-P.M.; writing—original draft preparation, M.-P.M.; writing—review and editing, M.G.W.; funding acquisition, M.G.W.; supervision, M.G.W. All authors have read and agreed to the published version of the manuscript.

Funding: M.G.W. and H.M. were funded by the National University of Singapore and the Singaporean Ministry of Education (grant no. R-148-000-282-133, WBS-148-0000-297-114). M.G.W. and M.-P.M. were funded by the LOEWE initiative of the State of Hessen and the Hessen Modellprojekte grant no. 552/17-34.

Institutional Review Board Statement: Not applicable.

Informed Consent Statement: Not applicable.

Data Availability Statement: Not applicable.

Acknowledgments: The authors acknowledge Dirk Beilke, Björn Fähler and Pharma Test Apparatebau AG (Hainburg, Germany) for providing them with PTDR release cells. 
Conflicts of Interest: E.F. is an employee of Eurofins PHAST Development GmbH \& Co. KG. This relationship had no influence on the scientific data presented in this article. All other authors declare no conflict of interest.

$\begin{array}{ll}\text { Abbreviations } & \\ \text { AAFE } & \text { absolute average fold error } \\ \text { AUC } & \text { area under the curve } \\ \text { BSA } & \text { bovine serum albumin } \\ \text { diclofenac-DEA } & \text { diclofenac diethylamine salt } \\ \text { DIMEC } & \text { Dialysis Membrane Permeation Calculator } \\ \text { DLS } & \text { dynamic light scattering } \\ \text { EV } & \text { extracellular vesicles } \\ \text { HPLC } & \text { High-performance liquid chromatography } \\ \text { HSA } & \text { human serum albumin } \\ \text { LOD } & \text { limit of detection } \\ \text { LOQ } & \text { limit of quantification } \\ \text { MWCO } & \text { molecular weight cut off } \\ \text { NIR } & \text { near-infrared light } \\ \text { PBS } & \text { phosphate-buffered saline } \\ \text { Ph. Eur. } & \text { European Pharmacopeia } \\ \text { PTDR } & \text { Pharma Test Dispersion Releaser } \\ \text { PTDR ReNo } & \text { PTDR release normalizer } \\ \text { PTFE } & \text { polytetrafluoroethylene } \\ \text { RC } & \text { regenerated cellulose } \\ \text { rPm } & \text { revolutions per minute } \\ \text { RRT } & \text { release response test } \\ \text { SD } & \text { standard deviation } \\ \text { SDS } & \text { sodium dodecyl sulfate } \\ \text { SEC } & \text { size exclusion chromatography } \\ \text { STELLA } & \text { Systems Thinking, Experimental Learning Laboratory with Animation } \\ \text { USP } & \text { United States Pharmacopeia } \\ \text { UV } & \text { ultraviolet light } \\ \text { Vis } & \text { visible light } \\ & \end{array}$

\section{References}

1. D'Mello, S.R.; Cruz, C.N.; Chen, M.L.; Kapoor, M.; Lee, S.L.; Tyner, K.M. The evolving landscape of drug products containing nanomaterials in the United States. Nat. Nanotechnol. 2017, 12, 523-529. [CrossRef]

2. Marques, M.R.C.; Choo, Q.; Ashtikar, M.; Rocha, T.C.; Bremer-Hoffmann, S.; Wacker, M.G. Nanomedicines-Tiny particles and big challenges. Adv. Drug Deliv. Rev. 2019, 151, 23-43. [CrossRef]

3. Mast, M.P.; Modh, H.; Champanhac, C.; Wang, J.W.; Storm, G.; Kramer, J.; Mailander, V.; Pastorin, G.; Wacker, M.G. Nanomedicine at the crossroads-A quick guide for IVIVC. Adv. Drug Deliv. Rev. 2021, 113829. [CrossRef]

4. Bunjes, H. Lipid nanoparticles for the delivery of poorly water-soluble drugs. J. Pharm. Pharmacol. 2010, 62, 1637-1645. [CrossRef]

5. Jung, F.; Nothnagel, L.; Gao, F.; Thurn, M.; Vogel, V.; Wacker, M.G. A comparison of two biorelevant in vitro drug release methods for nanotherapeutics based on advanced physiologically-based pharmacokinetic modelling. Eur. J. Pharm. Sci. 2018, 127, 462-470. [CrossRef] [PubMed]

6. Ashtikar, M.; Wacker, M.G. Nanopharmaceuticals for wound healing-Lost in translation? Adv. Drug Deliv. Rev. 2018, 129, 194-218. [CrossRef] [PubMed]

7. Zhao, Y.; Brown, M.B.; Jones, S.A. Pharmaceutical foams: Are they the answer to the dilemma of topical nanoparticles? Nanomedicine 2010, 6, 227-236. [CrossRef]

8. Salvioni, L.; Morelli, L.; Ochoa, E.; Labra, M.; Fiandra, L.; Palugan, L.; Prosperi, D.; Colombo, M. The emerging role of nanotechnology in skincare. Adv. Colloid Interface Sci. 2021, 293, 102437. [CrossRef] [PubMed]

9. Nothnagel, L.; Wacker, M.G. How to measure release from nanosized carriers? Eur. J. Pharm. Sci. 2018, 120, 199-211. [CrossRef]

10. Wacker, M.G.; Janas, C. Dialysis Cell for an In-Vitro Release Test Apparatus, Use of the Dialysis Cell and In-Vitro Release Test Apparatus. EP3047267A1, 17 September 2014.

11. Jablonka, L.; Ashtikar, M.; Gao, G.F.; Thurn, M.; Modh, H.; Wang, J.W.; Preuss, A.; Scheglmann, D.; Albrecht, V.; Roder, B.; et al. Predicting human pharmacokinetics of liposomal temoporfin using a hybrid in silico model. Eur. J. Pharm. Sci. 2020, 149, 121-134. [CrossRef] 
12. Modh, H.; Fang, D.J.; Ou, Y.H.; Yau, J.N.N.; Kovshova, T.; Nagpal, S.; Knoll, J.; Wallenwein, C.M.; Maiti, K.; Bhowmick, S.; et al. Injectable drug delivery systems of doxorubicin revisited: In vitro-in vivo relationships using human clinical data. Int. J. Pharm. 2021, 608, 121073. [CrossRef] [PubMed]

13. Wallenwein, C.M.; Nova, M.V.; Janas, C.; Jablonka, L.; Gao, G.F.; Thurn, M.; Albrecht, V.; Wiehe, A.; Wacker, M.G. A dialysis-based in vitro drug release assay to study dynamics of the drug-protein transfer of temoporfin liposomes. Eur. J. Pharm. Sci. 2019, 143, 44-50. [CrossRef] [PubMed]

14. Jablonka, L.; Ashtikar, M.; Gao, G.; Jung, F.; Thurn, M.; Preuss, A.; Scheglmann, D.; Albrecht, V.; Roder, B.; Wacker, M.G. Advanced in silico modeling explains pharmacokinetics and biodistribution of temoporfin nanocrystals in humans. J. Control. Release 2019, 308, 57-70. [CrossRef] [PubMed]

15. Janas, C.; Mast, M.P.; Kirsamer, L.; Angioni, C.; Gao, F.; Mantele, W.; Dressman, J.; Wacker, M.G. The dispersion releaser technology is an effective method for testing drug release from nanosized drug carriers. Eur. J. Pharm. Sci. 2017, 115, 73-83. [CrossRef] [PubMed]

16. Gao, G.F.; Thurn, M.; Wendt, B.; Parnham, M.J.; Wacker, M.G. A sensitive in vitro performance assay reveals the in vivo drug release mechanisms of long-acting medroxyprogesterone acetate microparticles. Int. J. Pharm. 2020, 586, 119540. [CrossRef] [PubMed]

17. Gao, G.F.; Ashtikar, M.; Kojima, R.; Yoshida, T.; Kaihara, M.; Tajiri, T.; Shanehsazzadeh, S.; Modh, H.; Wacker, M.G. Predicting drug release and degradation kinetics of long-acting microsphere formulations of tacrolimus for subcutaneous injection. J. Control. Release 2021, 329, 372-384. [CrossRef]

18. Yu, M.; Yuan, W.; Li, D.; Schwendeman, A.; Schwendeman, S.P. Predicting drug release kinetics from nanocarriers inside dialysis bags. J. Control. Release 2019, 315, 23-30. [CrossRef]

19. Xie, L.; Beyer, S.; Vogel, V.; Wacker, M.G.; Mantele, W. Assessing the drug release from nanoparticles: Overcoming the shortcomings of dialysis by using novel optical techniques and a mathematical model. Int. J. Pharm. 2015, 488, 108-119. [CrossRef]

20. Zhang, Y.; Geißen, S.-U. In vitro degradation of carbamazepine and diclofenac by crude lignin peroxidase. J. Hazard. Mater. 2010, 176, 1089-1092. [CrossRef]

21. Chinese Pharmacopoeia Commission. Chinese Pharmacoepia (Ch.P.), 10th ed.; Chinese Pharmacopoeia Commission: Beijing, China, 2015.

22. Smeraldi, J.; Ganesh, R.; Safarik, J.; Rosso, D. Statistical evaluation of photon count rate data for nanoscale particle measurement in wastewaters. J. Environ. Monit. 2012, 14, 79-84. [CrossRef]

23. Vysotskii, V.V.; Uryupina, O.Y.; Gusel'nikova, A.V.; Roldugin, V.I. On the feasibility of determining nanoparticle concentration by the dynamic light scattering method. Colloid J. 2009, 71, 739-744. [CrossRef]

24. Jung, F.; Thurn, M.; Krollik, K.; Li, D.; Dressman, J.; Alig, E.; Fink, L.; Schmidt, M.U.; Wacker, M.G. Sustained-release hot melt extrudates of the weak acid TMP-001: A case study using PBB modelling. Eur. J. Pharm. Sci. 2021, 160, 23-34. [CrossRef] [PubMed]

25. Jung, F.; Thurn, M.; Krollik, K.; Gao, G.F.; Hering, I.; Eilebrecht, E.; Emara, Y.; Weiler, M.; Gunday-Tureli, N.; Tureli, E.; et al. Predicting the environmental emissions arising from conventional and nanotechnology-related pharmaceutical drug products. Environ. Res. 2021, 192, 110219. [CrossRef] [PubMed]

26. Hansmann, S.; Miyaji, Y.; Dressman, J. An in silico approach to determine challenges in the bioavailability of ciprofloxacin, a poorly soluble weak base with borderline solubility and permeability characteristics. Eur. J. Pharm. Sci. 2018, 122, 186-196. [CrossRef] [PubMed]

27. Hansmann, S.; Darwich, A.; Margolskee, A.; Aarons, L.; Dressman, J. Forecasting oral absorption across biopharmaceutics classification system classes with physiologically based pharmacokinetic models. J. Pharm. Pharmacol. 2016, 68, 1501-1515. [CrossRef]

28. Janas, C.; Mostaphaoui, Z.; Schmiederer, L.; Bauer, J.; Wacker, M.G. Novel polymeric micelles for drug delivery: Material characterization and formulation screening. Int. J. Pharm. 2016, 509, 197-207. [CrossRef]

29. Wacker, M.G.; Lu, X.; Burke, M.; Nir, I.; Fahmy, R.; Zaidi, K. Testing the in-vitro product performance of nanomaterial-related drug products: View of the USP Expert Panel. Pharmacop. Forum 2021, 47, 1-14.

30. Bou-Abdallah, F.; Sprague, S.E.; Smith, B.M.; Giffune, T.R. Binding thermodynamics of Diclofenac and Naproxen with human and bovine serum albumins: A calorimetric and spectroscopic study. J. Chem. Thermodyn. 2016, 103, 299-309. [CrossRef]

31. Auler, J.; Espada, E.; Crivelli, E.; Quintavalle, T.B.G.; Kurata, A.; Stolf, N.; Issy, A.M.; Paschoa, O.E.D.; Danhof, M.; Breimer, D.; et al. Diclofenac plasma protein binding: PK-PD modelling in cardiac patients submitted to cardiopulmonary bypass. Braz. J. Med. Biol. Res. 1997, 30, 369-374. [CrossRef]

32. Wang, D.; Zhang, Y.; Liu, Y.-N.; Wang, J. Estimation of Binding Constants for Diclofenac Sodium and Bovine Serum Albumin by Affinity Capillary Electrophoresis and Fluorescence Spectroscopy. J. Liq. Chromatogr. Relat. Technol. 2008, 31, $2077-2088$. [CrossRef]

33. European Directorate for the Quality of Medicines \& Healthcare. European Pharmacopeia (Ph. Eur.), 10th ed.; Council of Europe: London, UK, 2021.

34. Olejnik, A.; Goscianska, J.; Nowak, I. Active Compounds Release from Semisolid Dosage Forms. J. Pharm. Sci. 2012, 101, 4032-4045. [CrossRef] [PubMed] 